\title{
Centimeter-Sized Single Crystal of a One-Dimensional Lead-Free Mixed-Cation Perovskite Ferroelectric for Highly Polarization Sensitive Photodetection
}

Weichuan Zhang, * Maochun Hong, and Junhua Luo*

\section{AUTHOR INFORMATION}

Corresponding Authors

Weichuan Zhang - CAS Key Laboratory of Nanosystem and Hierachical Fabrication CAS Center for Excellence in Nanoscience, National Center for Nanoscience and Technology, Beijing 100190, P. R. China; State Key Laboratory of Structure Chemistry, Fujian Institute of Research on the Structure of Matter, Chinese Academy of Sciences Fuzhou, Fujian, 350002 P. R. China; University of Chinese Academy of Sciences, Beijing 100049 , P.R. China; ID: orcid.org/0000-0002-3437-4153; *Email: weichuanzhang@163.com

Junhua Luo - State Key Laboratory of Structural Chemistry, Fujian Institute of Research on the Structure of Matter, Chinese Academy of Sciences, Fuzhou, Fujian 350002, P. R. China; University of the Chinese Academy of Sciences, Beijing 100049, P. R. China; ID: orcid.org/0000-0002-76737979; * Email: jhluo@ fjirsm.ac.cn

\section{Authors}

Maochun Hong - State Key Laboratory of Structural Chemistry, Fujian Institute of Research on the Structure of Matter, Chinese Academy of Sciences, Fuzhou, Fujian 350002, P. R. China; University of the Chinese Academy of Sciences, Beijing 100049, P. R. China; ID: orcid.org/00000002-1347-6046 


\section{Table of Contents}

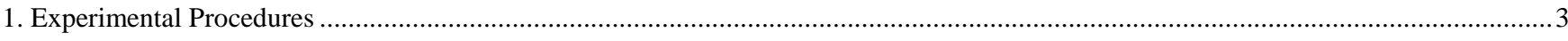

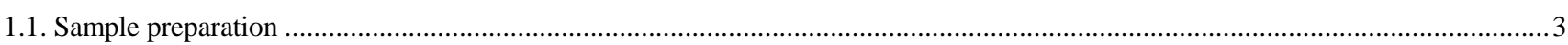

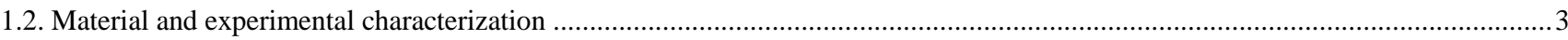

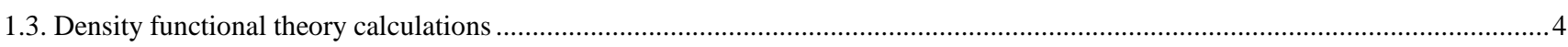

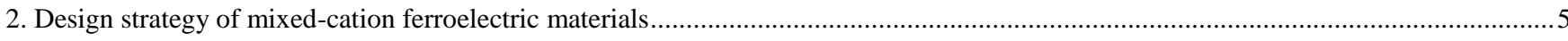

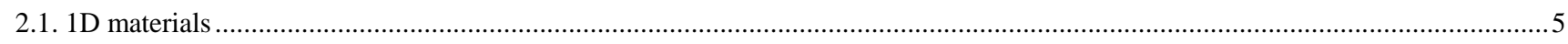

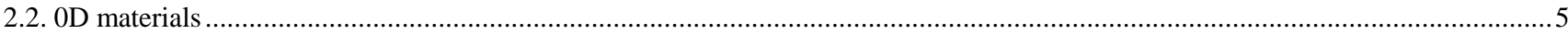

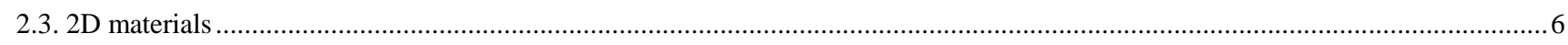

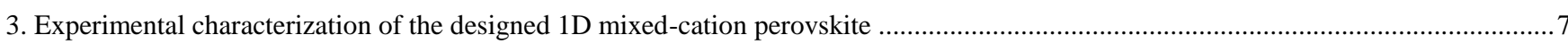

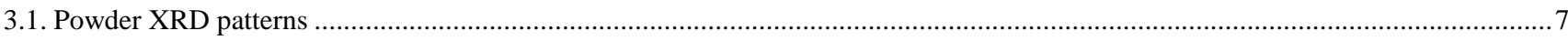

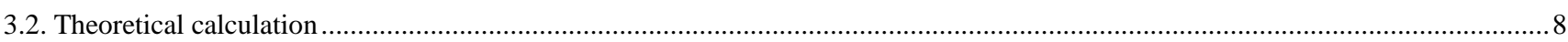

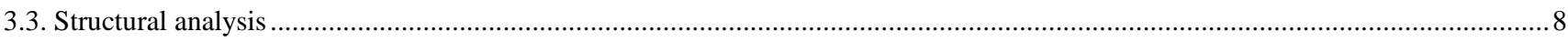

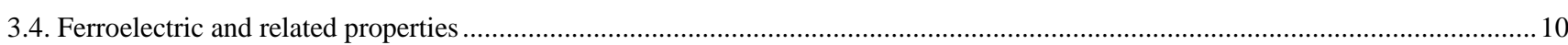

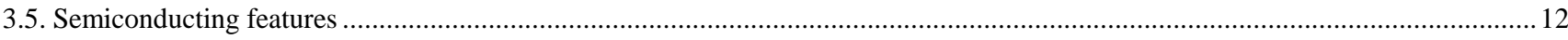

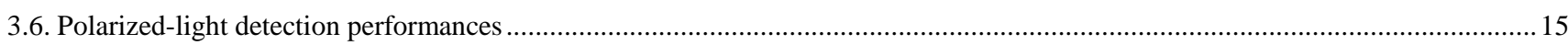

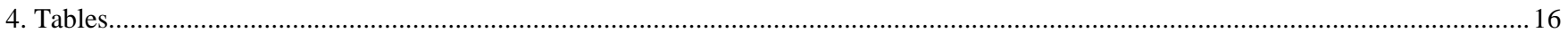

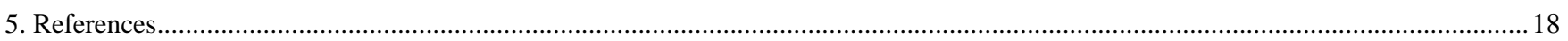




\section{Experimental Procedures}

\subsection{Sample preparation}

All manipulations were conducted in the air unless otherwise noted. Antimony trioxide (99.99\% metals basis) in a powder form Aladdin; Hydrobromic acid ( $48 \mathrm{wt}$. $\%$ in $\mathrm{H}_{2} \mathrm{O}$ ), methylamine ( $40 \mathrm{wt}$. $\%$ in $\mathrm{H}_{2} \mathrm{O}$ ), and $n$-propylamine (standard for $\mathrm{GC},>99.5 \%$ ) in a liquid form were purchased from Aladdin.

The prototype of $1 \mathrm{D}$ lead-free perovskite ( $n$-propylammonium $)_{2} \operatorname{SbBr}_{5}(\mathbf{I})$ was prepared by combining antimony trioxide $(291.5 \mathrm{mg}, 1 \mathrm{mmol})$ and $n$ propylamine ( $236.44 \mathrm{mg}, 4 \mathrm{mmol}$ ) in $5 \mathrm{~mL}$ of hydrobromic acid. Then, the mixture was heat and stirred briskly until dissolved. Subsequently, slowly cooling the solution to room temperature yielded yellow needlelike crystals. Similarly, single crystals of ( $n$ propylammonium)(methylammonium) $\operatorname{SbBr}_{5}$ (II) were synthesized under the same condiction, except for the addition of the second organic cation.

Large-size single crystals of ferroelectric material II were obtained by the slow temperature cooling process, where the freshly prepared crystals were re-dissolved as the precursor solution, and the corresponding translucent perovskite particulates with well-defined shapes were selected as seed crystals. Then, the temperature was lower down at a rate of around $1-2^{\circ} \mathrm{C}$ per day. As a result, high-quality centimeter-sized single crystals were obtained after a few days.

\subsection{Material and experimental characterization}

Crystal structure determination. The selected crystals were coated with oil, mounted on a loop, and transferred to a Bruker D8 Venture diffractometer equipped with a Bruker APEX-II CCD detector. Frames were collected using $\omega$ and $\psi$ scans with 18 -keV synchrotron radiation $(\lambda=$ $0.71073 \AA$ A). Unit-cell parameters were refined against all data. The crystal did not show significant decay during data collection. The space-group assignment was based on systematic absences, statistics, agreement factors for equivalent reflections, and successful refinement of the structure. The structure was solved by direct methods, expanded through successive difference Fourier maps using the Olex 2, and refined against all data using the SHELXT software package. ${ }^{1-4}$ Weighted $\mathrm{R}$ factors, $\mathrm{R}_{\mathrm{w}}$, and all goodness-of-fit indicators are based on F2. Twin laws were determined using Platon. Hydrogen atoms were inserted at idealized positions and refined using a riding model with an isotropic thermal parameter 1.2 times that of the attached carbon or nitrogen atom for $\mathrm{CH}_{2}$ and $\mathrm{NH}_{3}$ groups or 1.5 times that of the attached carbon atom for $\mathrm{CH}_{3}$ groups. Details regarding the data quality and a summary of the residual values of the refinements are listed in cif file. The single crystal data and selected bond lengths $(\AA)$ and Bond Angles are listed in Table 1.

UV-vis-NIR diffuse reflectance spectroscopy. The UV-vis-NIR diffuse reflection data were obtained at room temperature and scan wavelength is between $300 \mathrm{~nm}$ and $1000 \mathrm{~nm}$ on a LAMBDA $950 \mathrm{UV} / \mathrm{Vis}$ Spectrophotometer. The $\mathrm{BaSO}_{4}$ powder sample was used as a standard (100\% reflectance) and Absorption $(K / S)$ data were calculated from the following Kubelka-Munk function: $K / S=(1-R)^{2} / 2 R$, where $R$ is the reflectance, $K$ is the absorption, and $\mathrm{S}$ is the scattering. ${ }^{5}$

Powder X-ray diffraction. Powder X-ray diffraction (PXRD) for II was performed on a Miniflex600 X-ray diffractometer at different temperatures The diffraction patterns were collected in the $2 \theta$ range of $5^{\circ}-50^{\circ}$ with a step size of $0.5^{\circ}$. The experimental power and film PXRD patterns obtained at room temperature, and simulated powder XRD pattern were acquired by the software of mercury.

Characterization of ferroelectric properties .The differential scanning calorime was performed using a NETZSCH DSC 200 F3 DSC instrument in the temperature range of 200-300 K for several cycles. The crystalline samples were placed in aluminum crucibles that were heated and cooled with a rate of $10 \mathrm{~K} / \mathrm{min}$ under the nitrogen atmosphere.

Dielectric constant tests were performed on the pressed-powder pellets that were covered by silver conducting glue. A Tonghui TH2828A analyzer was used to record the temperature variability of the real part $\left(\varepsilon^{\prime}\right)$ with different frequencies.

Ferroelectric polarization vs electric field $(P-E)$ hysteresis loops were measured with the applied electric field parallel to its polar c-axis.

Bulk single crystal samples of II with were used to measure the temperature-dependent the second harmonic generation (SHG) properties. A Nd: YAG laser ( $\lambda=1064 \mathrm{~nm}$, the pulse duration is $5 \mathrm{~ns}$ and peak power is $\sim 1.6 \mathrm{MW}$ ) was used as the fundamental light source, and SHG signals were collected using a Fluorescence Spectrometer (FLS 920, Edinburgh Instruments) equipped with the variable-temperature system. The SHG intensity of II was measured through a semi-quantitative comparison with that of standard $\mathrm{KH}_{2} \mathrm{PO}_{4}$ (i.e. KDP).

Conductivity studies. Single crystal samples $(\sim 1.8 \mathrm{~mm}$ in length and $\sim 1.5 \mathrm{~mm}$ in width) were cut to obtain smooth surfaces for conductivity Studies Silver paint (PELCO was brushed onto both sides of the disk-shaped pellets to serve as the electrode. Current-Temperature curves of the device performed by a Model 6517B Electrometer with a ST-102D Probe station. Electrical resistivity measurements were performed in air with a bias of $5 \mathrm{~V}$ in a temperature range of $225 \mathrm{~K}$ to $430 \mathrm{~K}$.

The electrical conductivity $(\sigma)$ can then be calculated as:

$$
\sigma=d I / V S
$$

Where $\mathrm{S}$ is the uniform cross-section of the sample and $\mathrm{d}$ is the thickness of the sample. 
The relationship between electrical conductivity, activation energy, and the temperature is shown in the following expressions:

$$
\ln \sigma=\ln \mathrm{A}-\mathrm{Ea} / 2 \mathrm{kT}
$$

Where $\sigma$ is the electrical conductivity, $\mathrm{A}$ is representative of Arrhenius type activation energy (negligible temperature dependence), Ea is the activation energy, $\mathrm{k}$ is the Boltzmann constant and $\mathrm{T}$ is the absolute temperature in Kelvin. From the equations, it can be seen that the activation energy can be determined by the slope of a logarithmic plot of $\sigma$ versus $1 / 2 \mathrm{kT}$.

Photoresponse measurements. The $I-V$ measurements were carried out using a Keithley $6517 \mathrm{~B}$ source meter with a Linkam LTSE420. All the electrical measurements were performed under atmosphere and at room temperature.

Polarized-Light Detection. the polarized-light detection measurements were carried out using a Keithley 6517B source meter with a Linkam LTSE420. The light was incident along (110) and linearly polarized along (001) and (-110) axes directions, which correspond to the optical absorbance maximum and minimum, respectively. Under polarized-light irradiation, photocurrent is dependent on the polarization angle well following a sine function in the polar coordinate.

\subsection{Density functional theory calculations}

Density function theory (DFT) calculations were performed with the Cambridge Sequential Total Energy Package (CASTEP). ${ }^{6,7}$ The exchangecorrelation functional was described by a generalized gradient approximation (GGA) with PerdewBurke-Ernzerhof functional for solids (PBEsol) scheme. ${ }^{8}$ The interactions between the ionic cores and the electrons were described by the norm-conserving pseudopotential. ${ }^{9}$ The following orbital electrons were treated as valence electrons: $\mathrm{Sb} 4 \mathrm{~d}^{10} 5 \mathrm{~s}^{2} 5 \mathrm{p}^{3} ; \mathrm{Br} 4 \mathrm{~s}^{2} 4 \mathrm{p}^{5}$; C $2 \mathrm{~s}^{2} 2 \mathrm{p}^{2} ; \mathrm{N} 2 \mathrm{~s}^{2} 2 \mathrm{p}^{3}$ and $\mathrm{H} 1 \mathrm{~s}^{1}$. The numbers of plane waves included in the basis sets were determined by a cut-off energy $850 \mathrm{eV}$ for II. To achieve the accurate density of the electronic states, the k-space integrations were done with Monk Horst-Pack grids with a $2 \times 3 \times 4$ k-point. The other parameters and convergent criteria were the default values of CASTEP code. 


\section{Design strategy of mixed-cation ferroelectric materials}

\subsection{D materials}

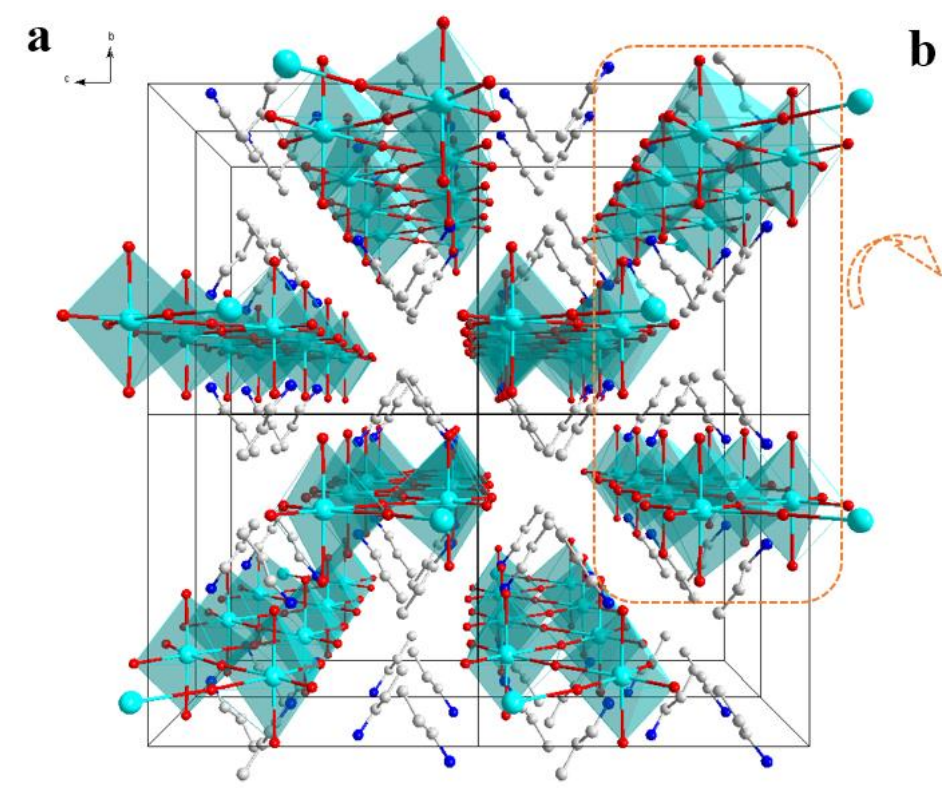

b

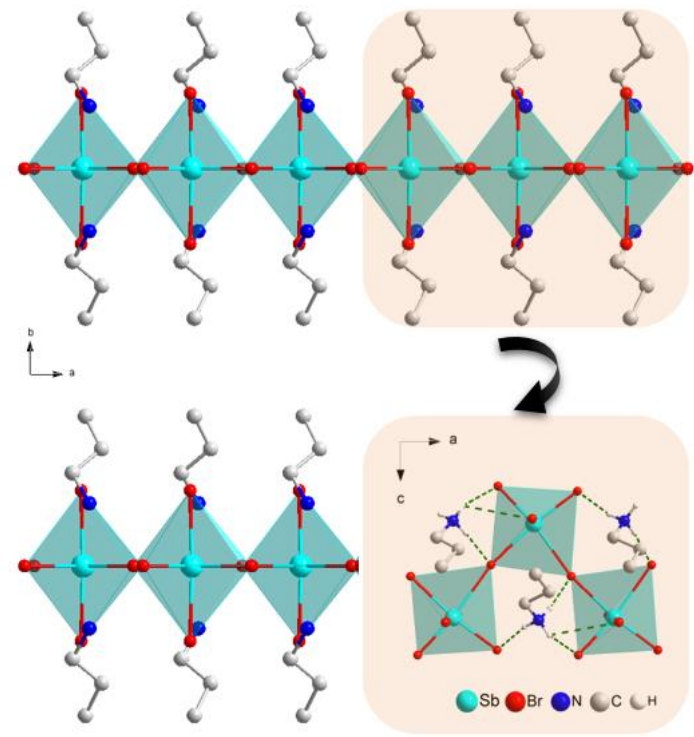

Figure S1. Crystal structures of the prototypical 1D lead-free perovskite derivative I. (a) Packing diagram of the crystal structure along the a axis. Hydrogen atoms were omitted for clarity. (b) Enlarged view of inorganic chain. Among organic fillers behave as the "spacer" to isolate each inorganic chains along the out-of-chain direction. These organic cations bond to the $\mathrm{SbBr}_{6}$ octahedra through $\mathrm{N}-\mathrm{H} \cdots \mathrm{Br}$ hydrogen bonds, as shown in pale orange background.

\subsection{D materials}

$\mathbf{a}$
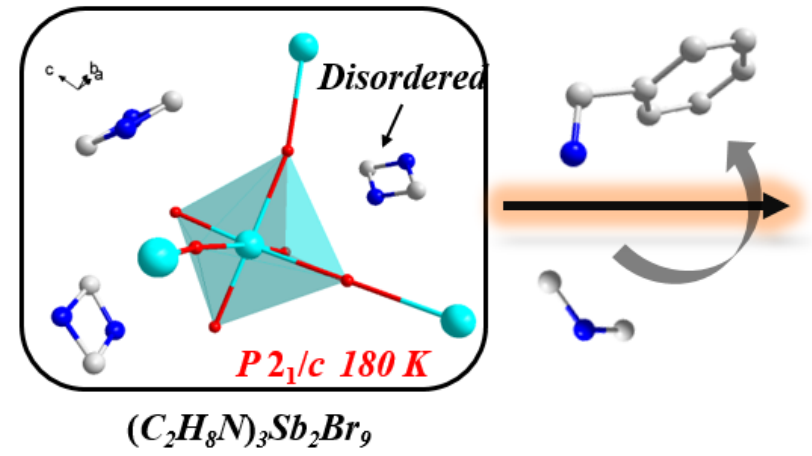

C

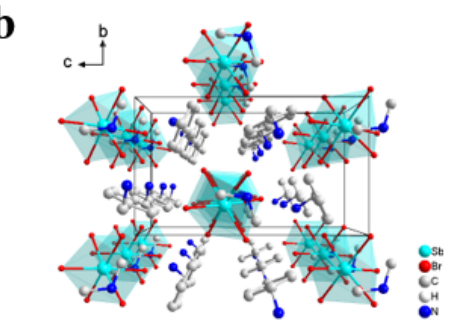

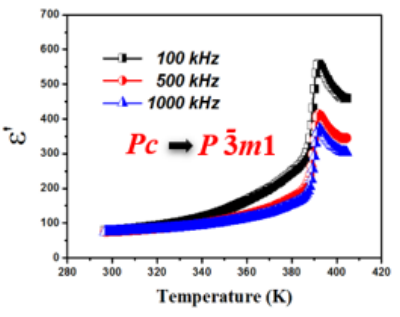

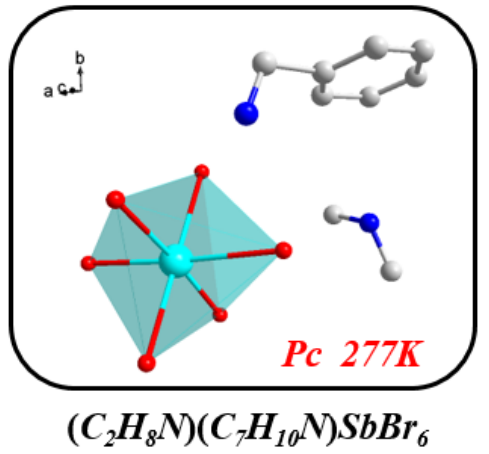

d

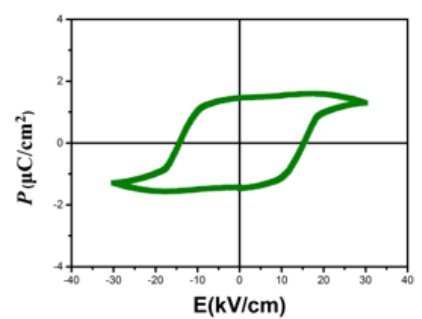

Figure S2. Design and characterization of a mononuclear $0 \mathrm{D}$ hybrid perovskite. (a) Schematic diagram for the design of $0 \mathrm{D}$ mononuclear hybrid perovskite motif of $\left(\mathrm{C}_{2} \mathrm{H}_{8} \mathrm{~N}\right)\left(\mathrm{C}_{7} \mathrm{H}_{10} \mathrm{~N}\right) \mathrm{SbBr}_{6}$, alloying the organic phenylmethanaminium cation into the prototype (dimethylammonium) $\mathrm{SbBr}_{6}{ }^{10}(\mathbf{b}) \mathrm{Packing}$ diagram viewed along the a-axis at low temperature phase. (c) The temperature dependence of dielectric real part $\varepsilon$ ' at various frequencies. (d) $P-E$ hysteresis loop measured at $350 \mathrm{~K}$ with the frequency of $25 \mathrm{~Hz}$. 


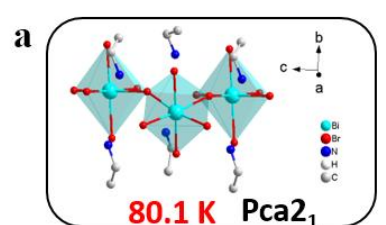

$\left(\mathrm{C}_{2} \mathrm{H}_{5} \mathrm{NH}_{3}\right)_{2} \mathrm{BiBr}_{5}$

C

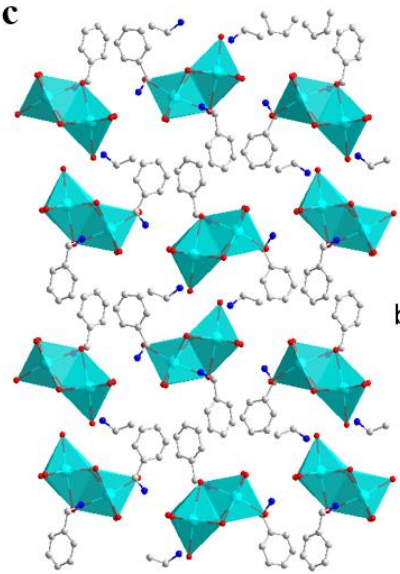

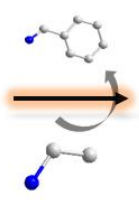

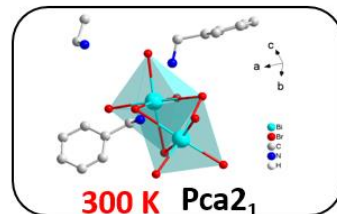

$\left(\mathrm{C}_{2} \mathrm{H}_{5} \mathrm{NH}_{3}\right)\left(\mathrm{C}_{6} \mathrm{H}_{5} \mathrm{CH}_{2} \mathrm{NH}_{3}\right)_{2} \mathrm{Bi}_{2} \mathrm{Br}_{9}$
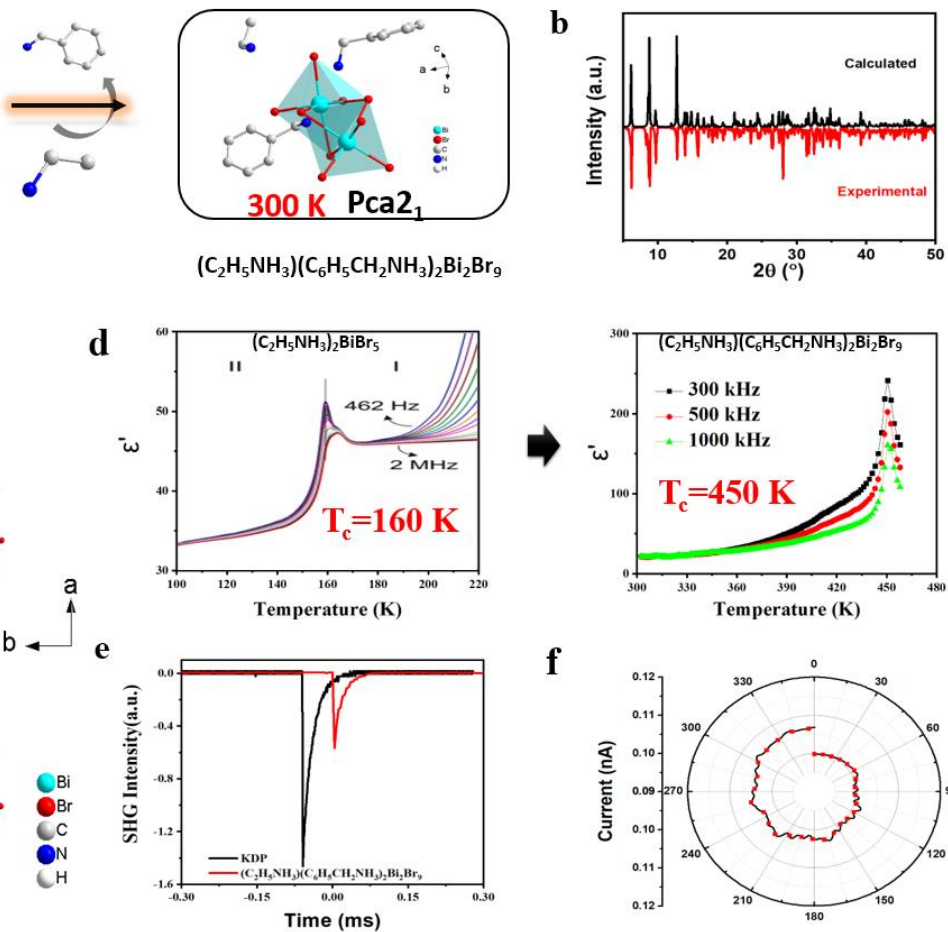

f

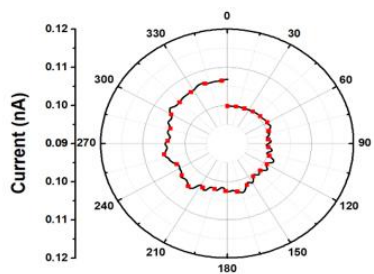

Figure S3. Design and characterization of a 0D hybrid perovskite. (a) Schematic diagram for the design of ethylamine-based perovskite $\left(\mathrm{C}_{2} \mathrm{H}_{8} \mathrm{~N}\right)\left(\mathrm{C}_{6} \mathrm{H}_{5}\right.$ $\left.\mathrm{CH}_{2} \mathrm{NH}_{3}\right)_{2} \mathrm{Bi}_{2} \mathrm{Br}_{9}$, alloying the organic $\mathrm{C}_{6} \mathrm{H}_{5} \mathrm{CH}_{2} \mathrm{NH}_{3}$ cation into the prototype $\left(\mathrm{C}_{2} \mathrm{H}_{8} \mathrm{~N}\right)_{2} \mathrm{BiBr}_{5}{ }^{11}$ (b) Powder XRD patterns of the designed ethylamine-based perovskite. (c) Packing diagram viewed along the b-axis at low temperature phase. (d) The temperature dependence of dielectric real part $\varepsilon$ ' at various frequencies, and compared with its prototype of $\left(\mathrm{C}_{2} \mathrm{H}_{8} \mathrm{~N}\right)_{2} \mathrm{BiBr}_{5}$. (e) Oscilloscope trace of SHG signals the designed ferroelectric material. The potassium dihydrogen phosphate crystal (KDP) was used as the reference. (f) Polarization dependence of the angle-resolved photocurrent under incident polarized light, measured under a 405 laser at room temperature.

\subsection{D materials}

a

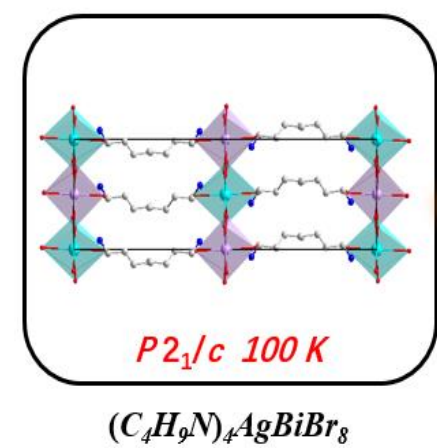

b

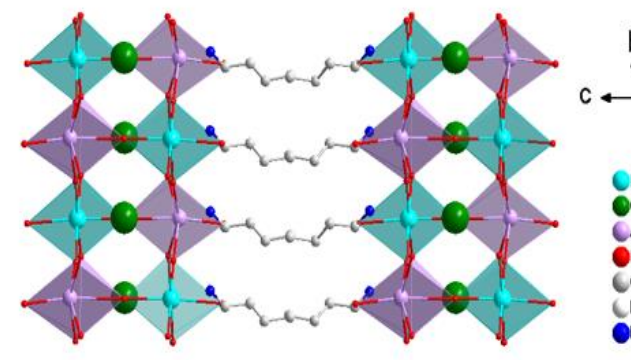

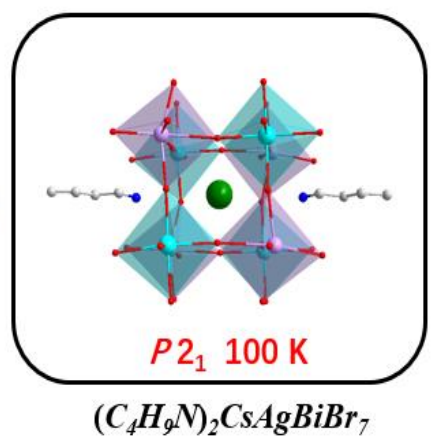

c

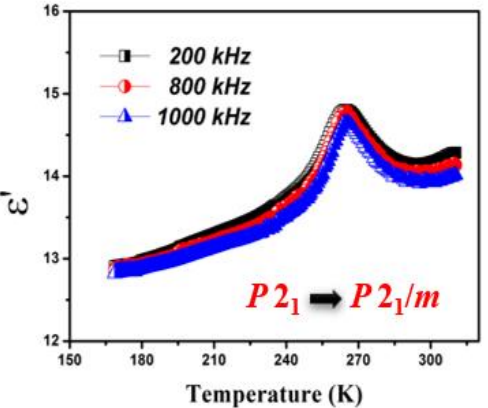

Figure S4. Design and characterization of a 2D hybrid perovskite. (a) Schematic diagram for the design of $2 \mathrm{D}$ hybrid perovskite motif of $\left(\mathrm{C}_{4} \mathrm{H}_{9} \mathrm{~N}\right)_{2} \mathrm{Cs} \mathrm{AgBi}_{\mathrm{B}} \mathrm{Br}_{7}$ alloying the cesium cations into the prototype $\left(\mathrm{C}_{4} \mathrm{H}_{9} \mathrm{~N}\right)_{4} \mathrm{AgBiBr}$. (b) Packing diagram viewed along the a-axis at low temperature phase. (c) The temperature dependence of dielectric real part $\varepsilon$ ' at various frequencies. This work has recently been validated and published. ${ }^{12,13}$ 
$\mathbf{a}$

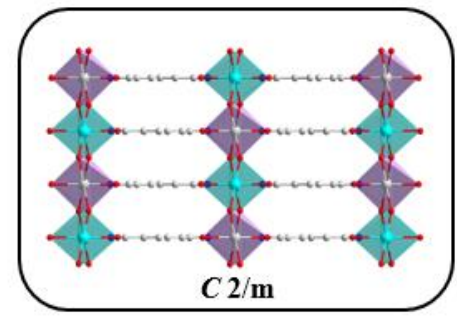

(n-propylammonium) ${ }_{4} \mathrm{AgBiBr}_{8}$

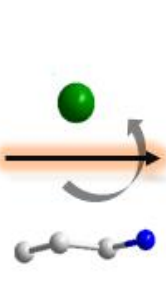

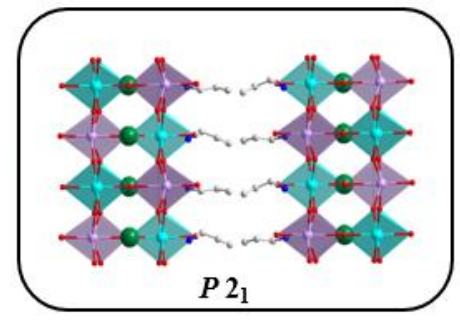

(n-propylammonium) ${ }_{2} \mathrm{CsAgBiBr}_{7}$
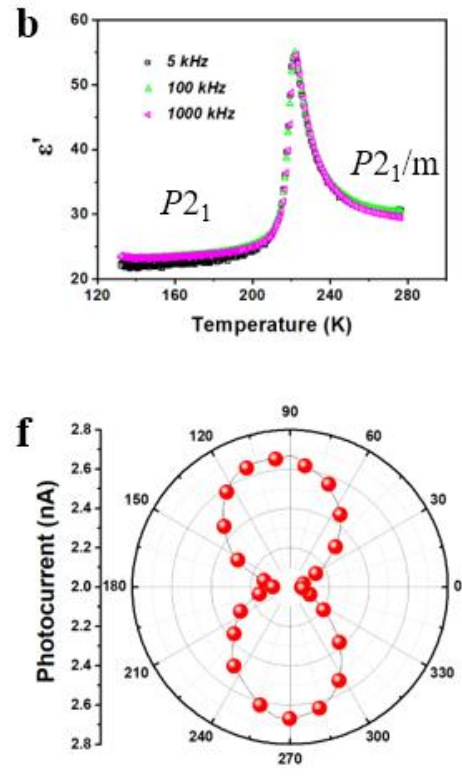

c

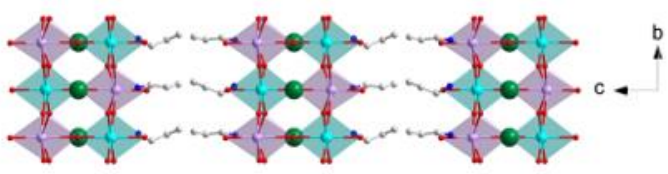

d

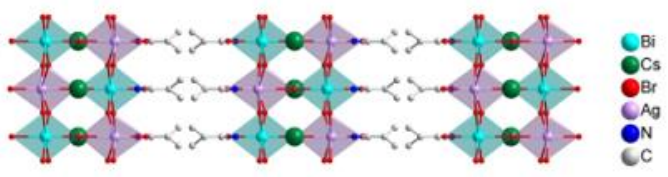

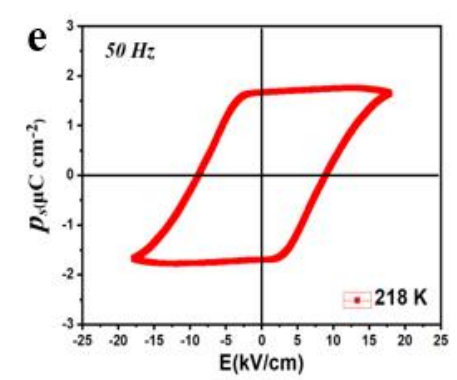

Figure S5. Design and characterization of a 2D $\boldsymbol{n}$-propylammonium-based hybrid perovskite. (a) Schematic diagram for the design of ethylamine-based perovskite

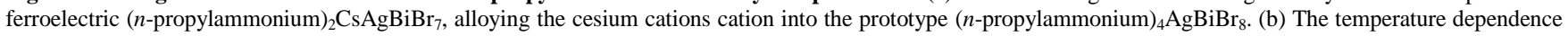
of dielectric real part $\varepsilon$ ' at various frequencies. (c, d) Packing viewed in the phase ferroelectric and paraelectric phase. (e) $P-E$ hysteresis loop measured at room temperature with the frequency of $25 \mathrm{~Hz}$. (f) Polarization dependence of the angle-resolved photocurrent under incident polarized light.

\section{Experimental characterization of the designed 1D mixed-cation perovskite}

\subsection{Powder XRD patterns}

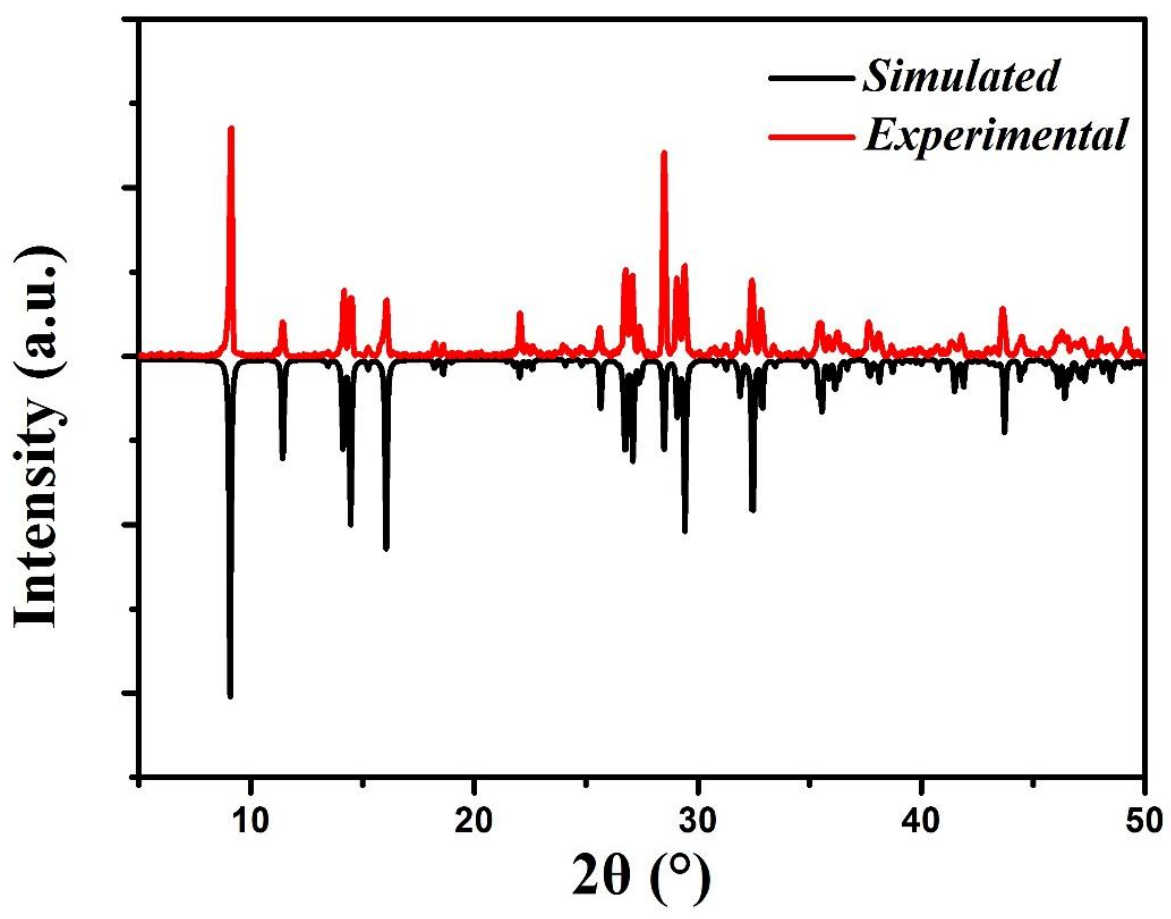

Figure S6. Powder XRD patterns of perovskite II 


\subsection{Theoretical calculation}

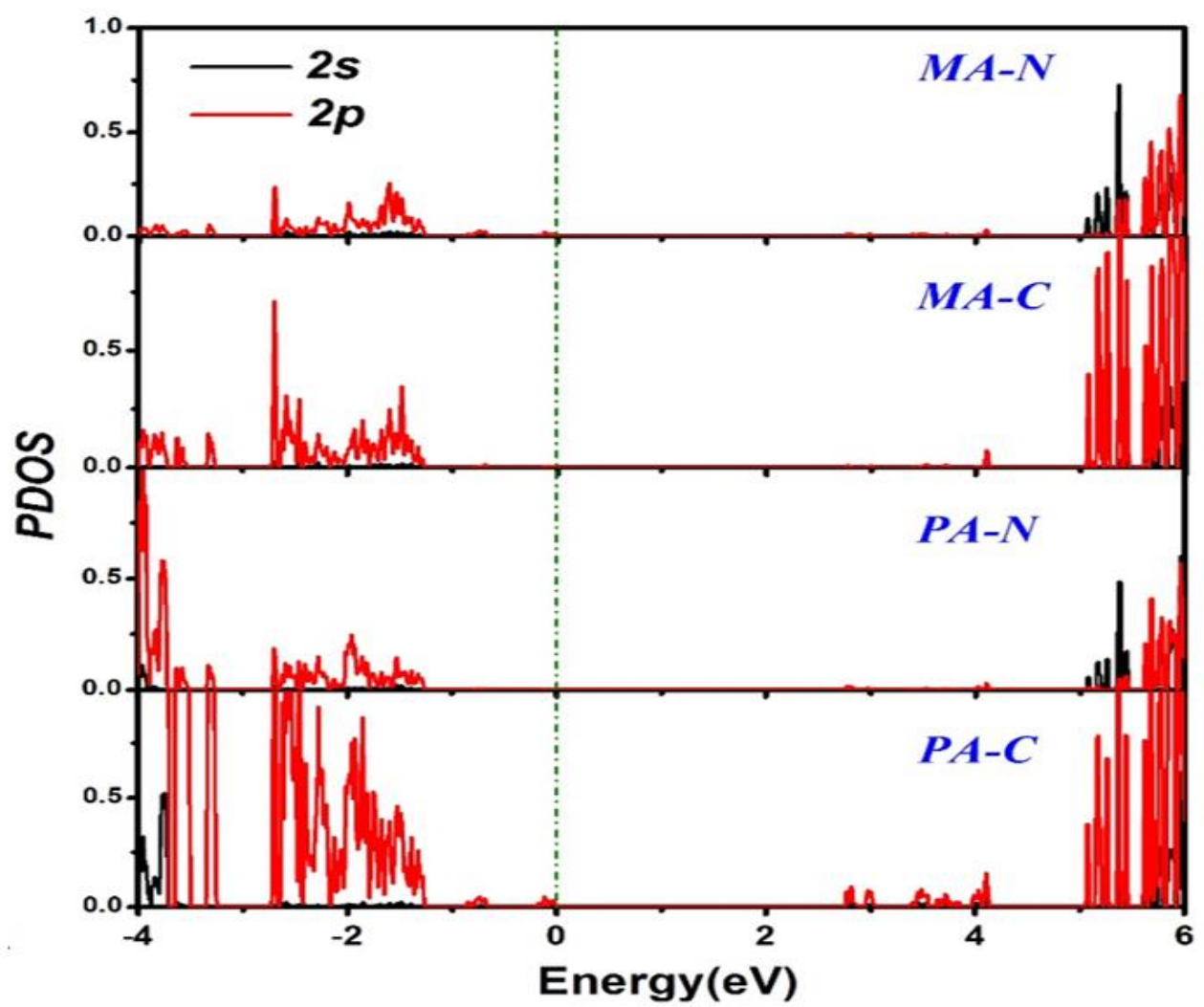

Figure S7. Calculated projected density of states based on the structure of perovskite II.

\subsection{Structural analysis}

a
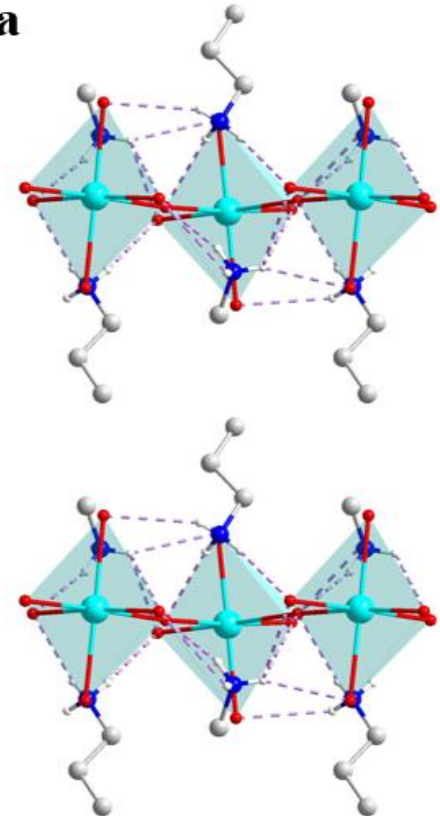

b
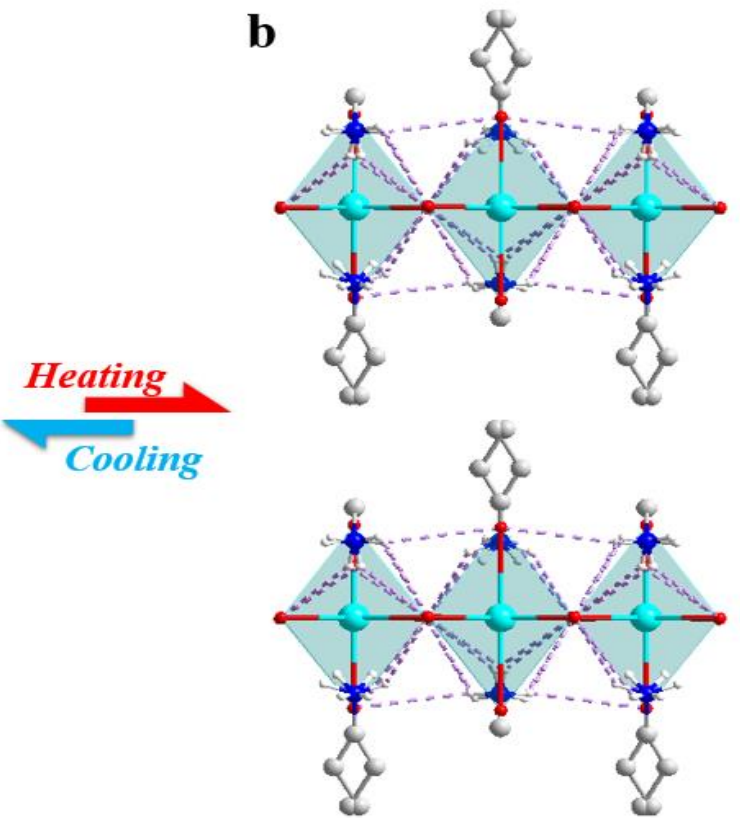

Figure S8. Crystal structures with the $\mathbf{N}-\mathbf{H} \cdots \mathbf{B r}$ hydrogen bonds. (a) The packing view of II at $200 \mathrm{~K}$. (b) The packing illustration of the high temperature phase at 260K. Partial H atoms were omitted for clarity. 
$\mathbf{a}$

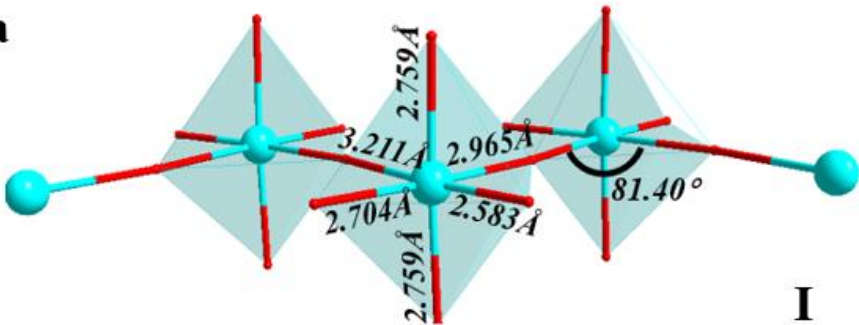

$\mathbf{b}$
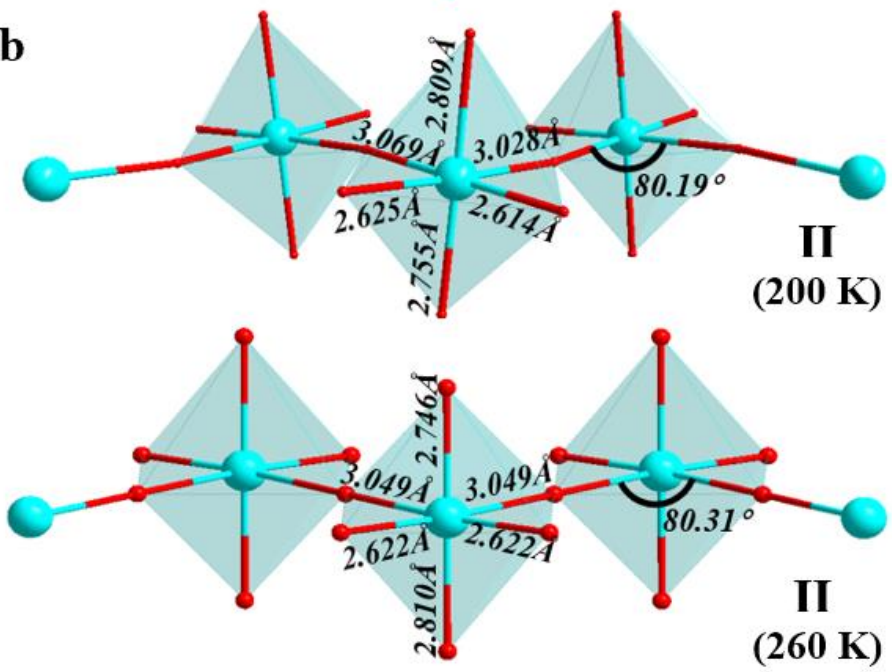

Figure S9. Inorganic metal framework. (a) The prototype inorganic framework of perovskite I. (b) The inorganic framework of mix-cation hybrid perovskite ferroelectric II at 200 and $260 \mathrm{~K}$.

$\mathbf{a}$

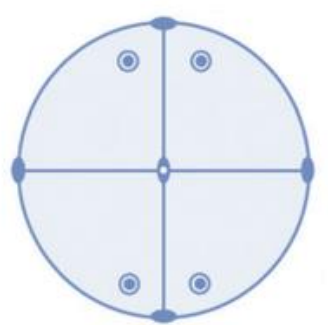

Paraelectric phase

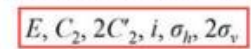

b

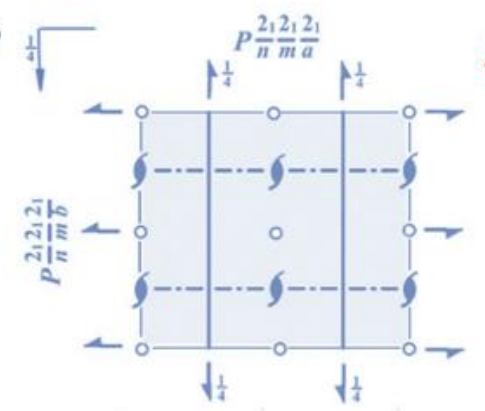

Pnma (NO.62)

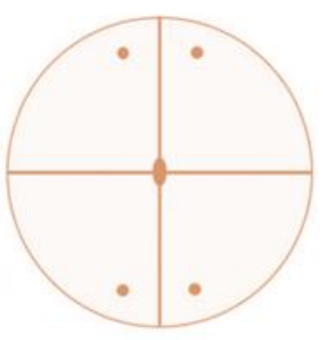

ferroelectric phase

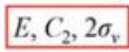

Heating

Symmetry restoration

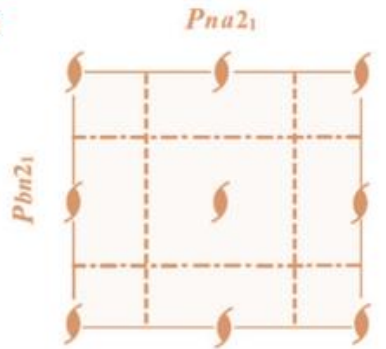

$\operatorname{Pna2}_{1}($ NO.33)

Figure S10. Symmetry breaking occurs with an Aizu notation of $\mathbf{m m m F m m 2 . ~ ( a ) ~ E q u a t o r i a l ~ p l a n e ~ p r o j e c t i o n ~ o f ~ p o i n t ~ g r o u p s ~} m m m$ (D2h) in the paraelectric phase and $m m 2(\mathrm{C} 2 \mathrm{v})$ in the ferroelectric phase. (b) Spatial symmetry operations of space groups Pnma in the paraelectric phase and Pna2 $2_{1}$ in the ferroelectric phase. 


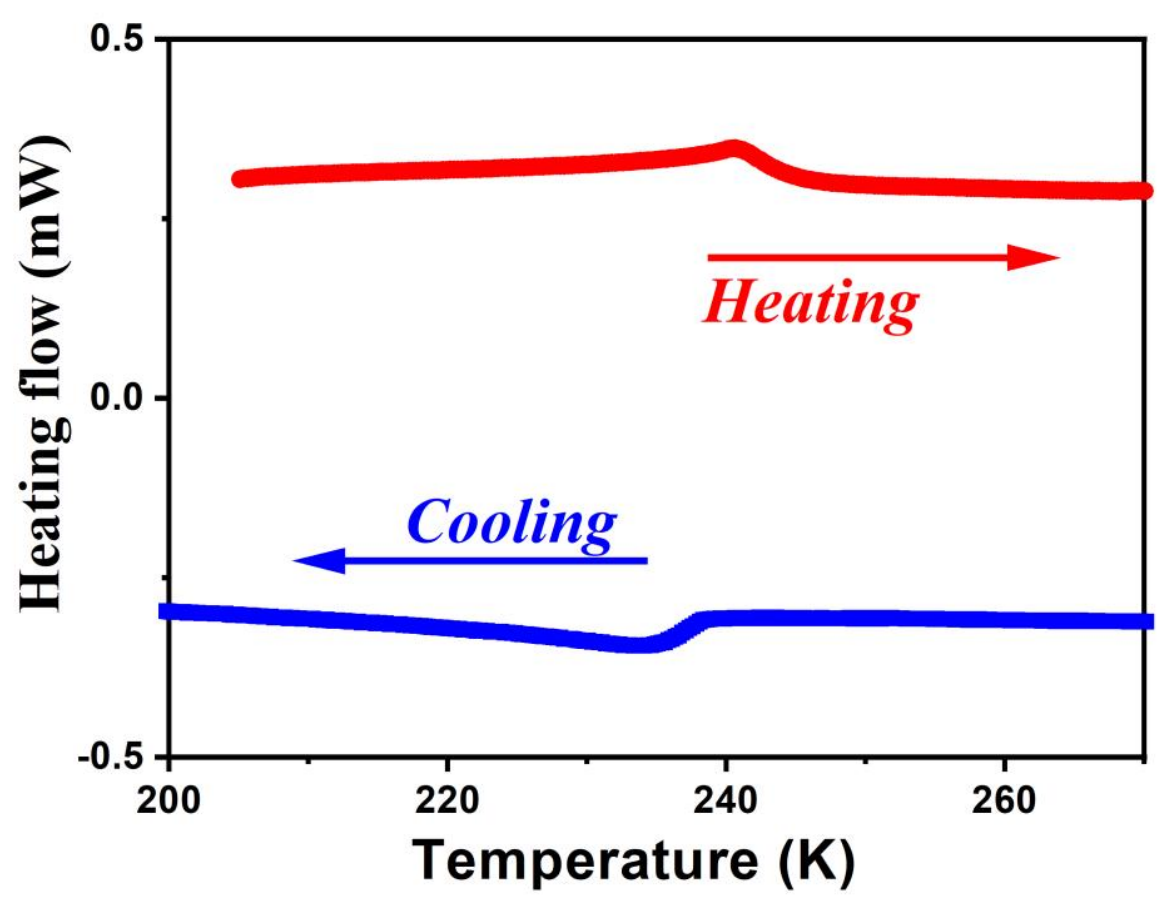

Figure S11. DSC curves of perovskite II in a heating-cooling run.

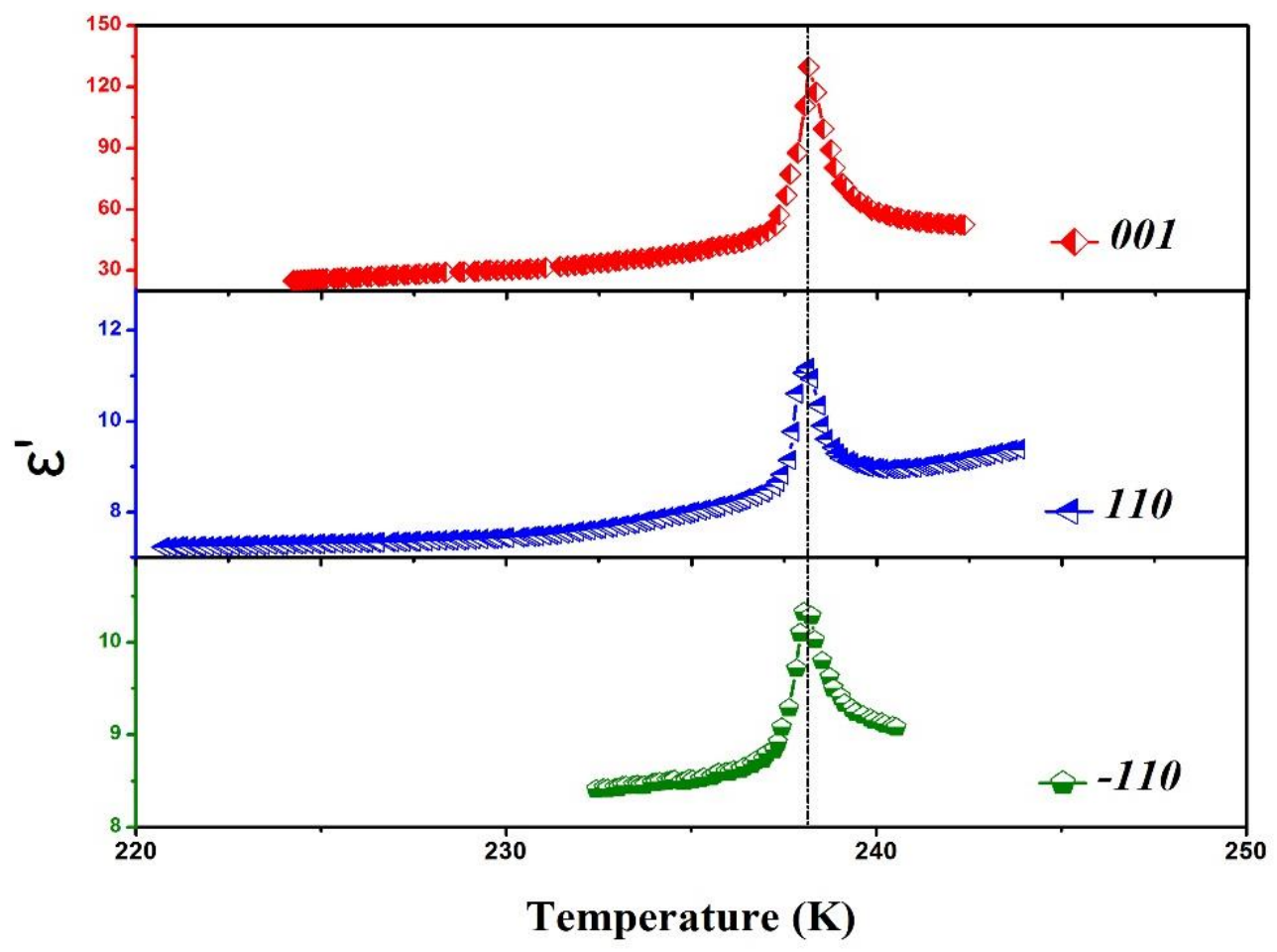

Figure S12. Dielectric properties of II. Comparison of real parts measured along different directions. 


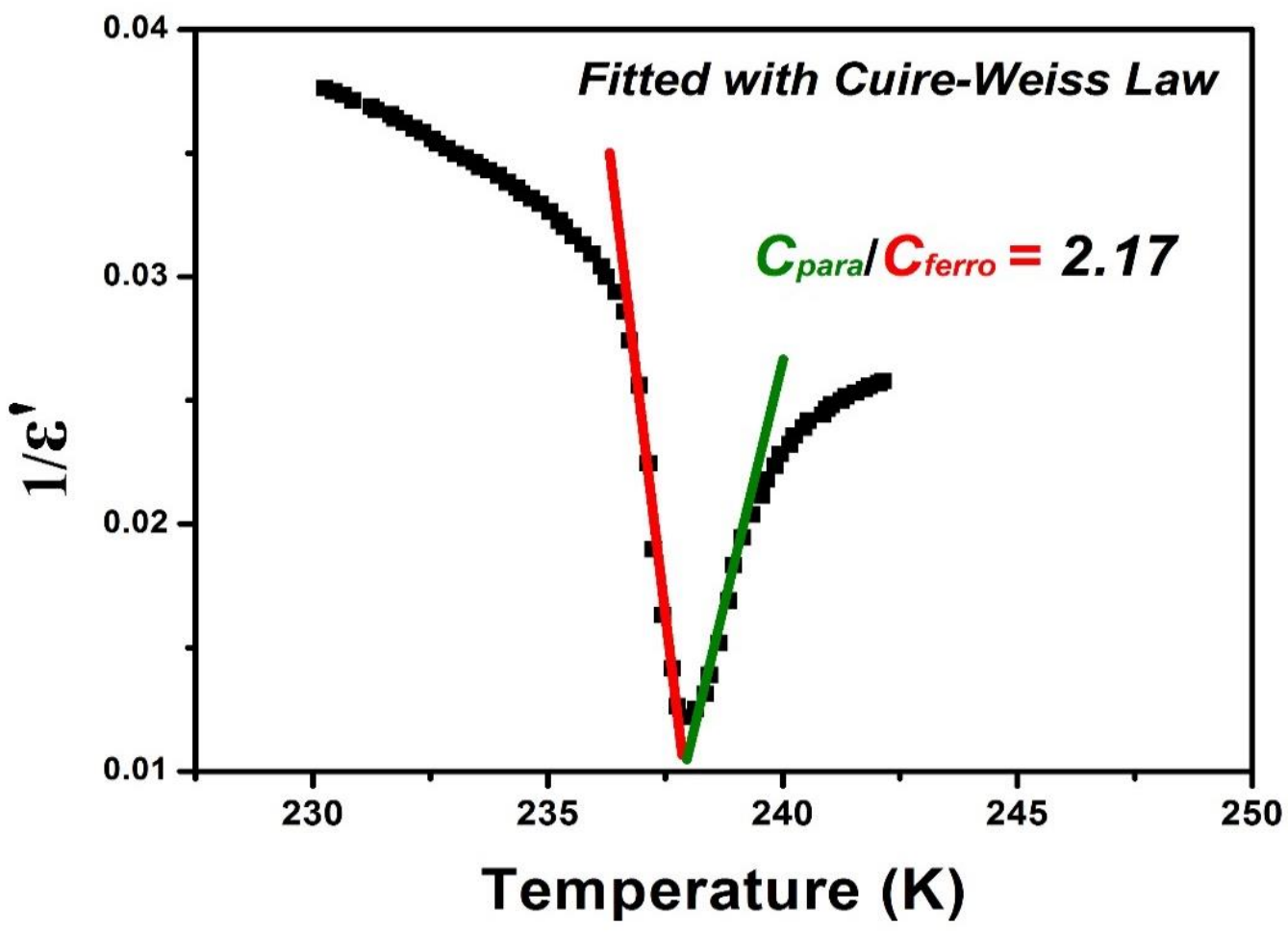

Figure S13. Dielectric properties of II. The reciprocal dielectric constant $1 / \varepsilon^{\prime}$ at $500 \mathrm{kHz}$ as a function of temperature.

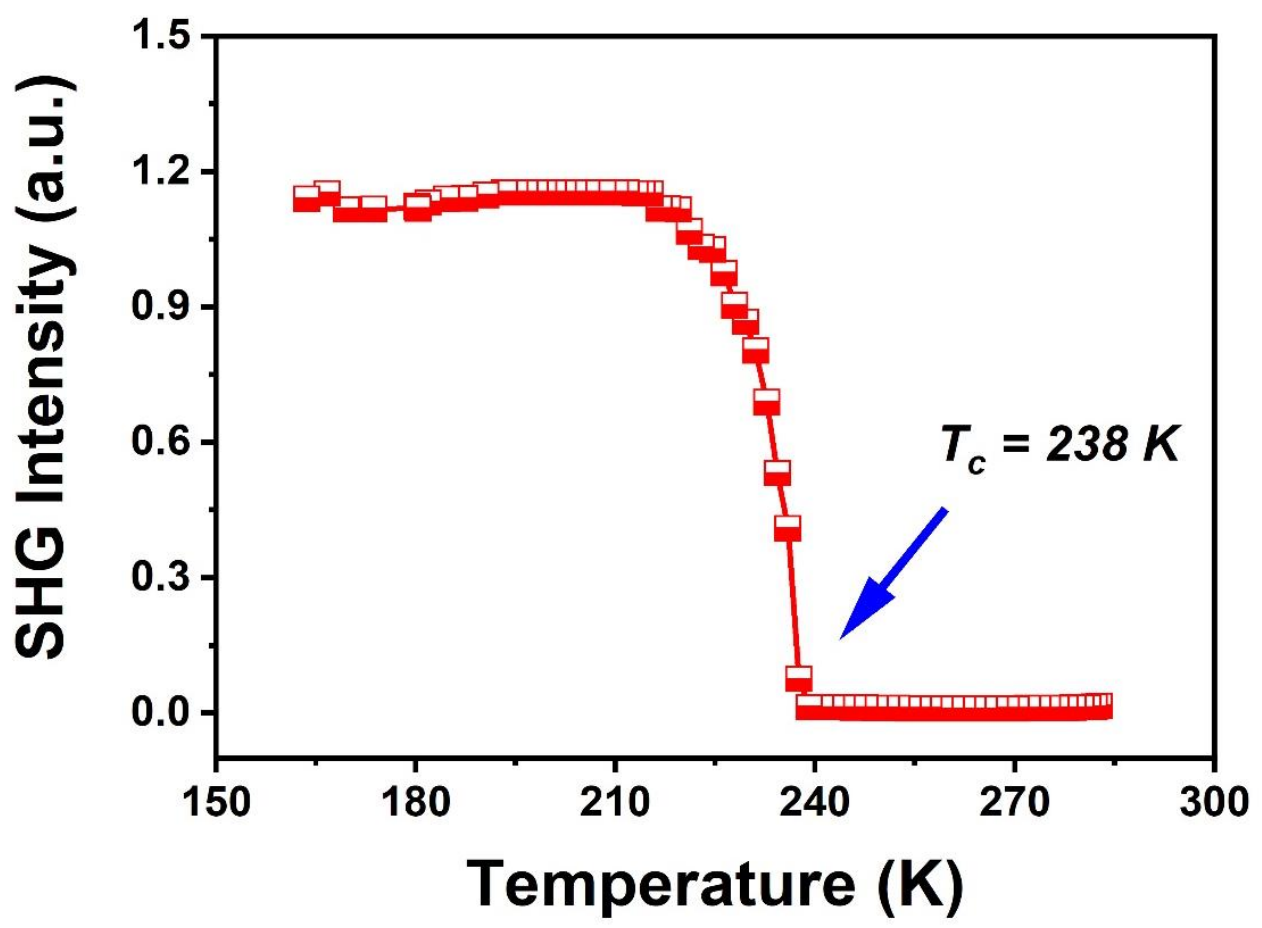

Figure S14. SHG properties of II. SHG intensity as a function of temperature. 

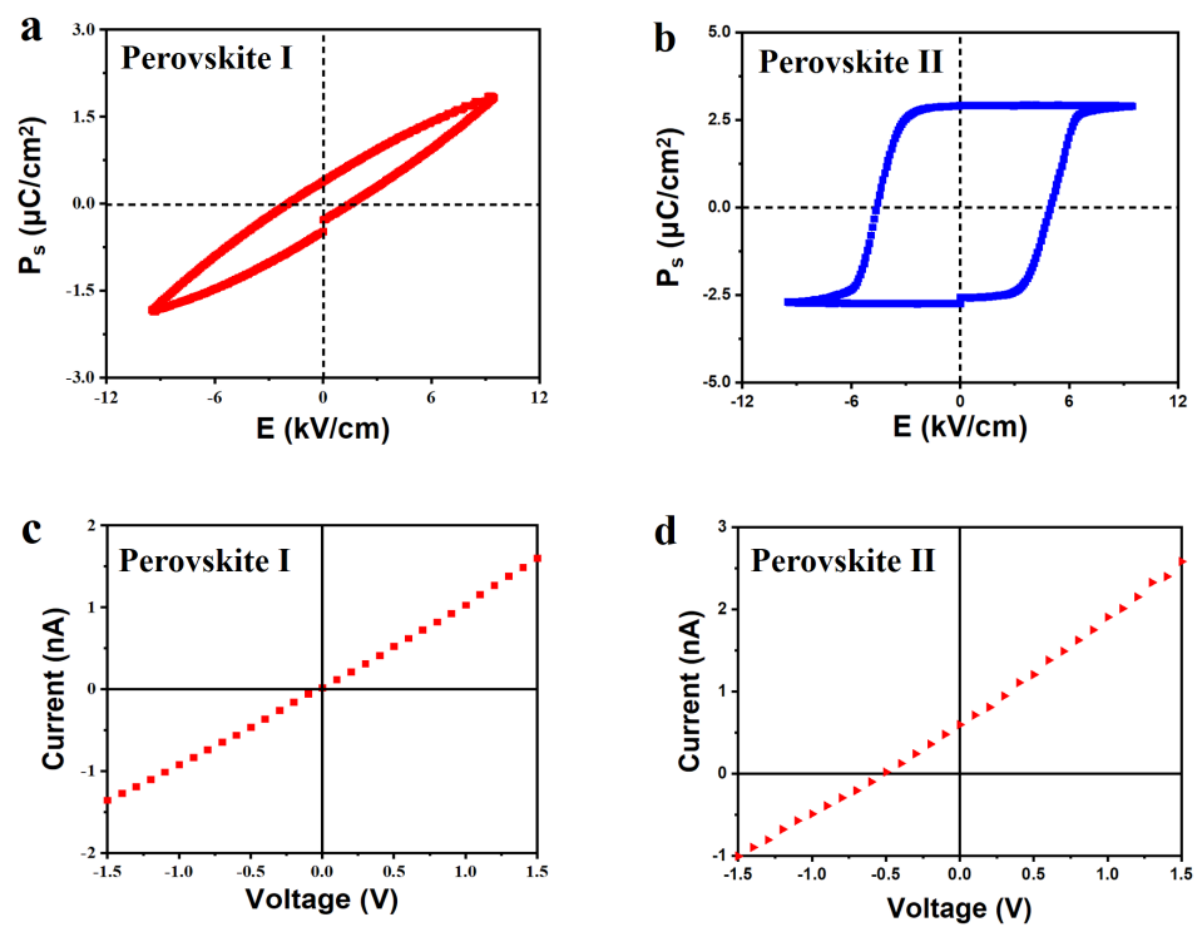

Figure S15. Performance comparison of perovskite I and II. (a, b) $P-E$ hysteresis loops of perovskite I and II measured at 236 K. (c, d) Photocurrent dependence of voltage bias illuminated with a $405 \mathrm{~nm}$ laser at $220 \mathrm{~K}$.

\subsection{Semiconducting features}

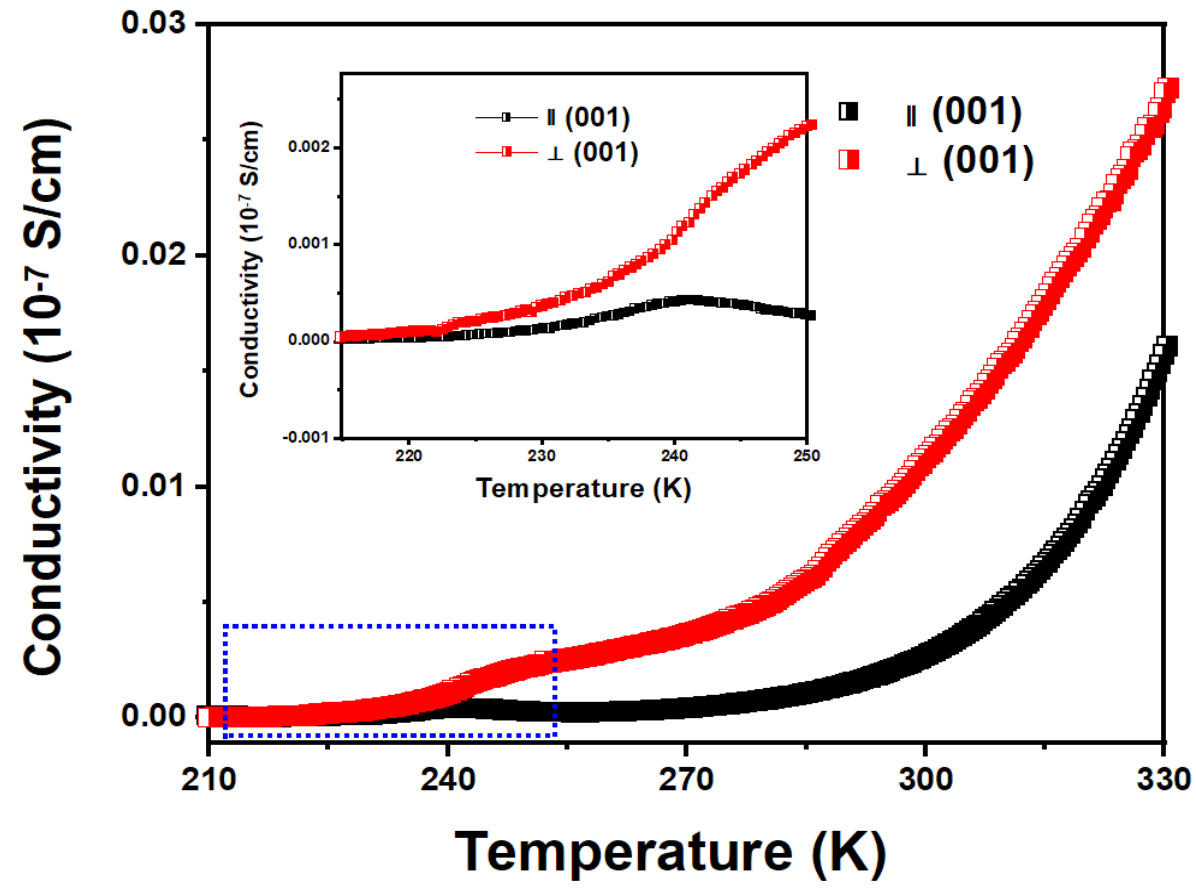

Figure S16. Temperature-dependent conductivity curve of single-crystal samples II along and perpendicular to (001) direction. 


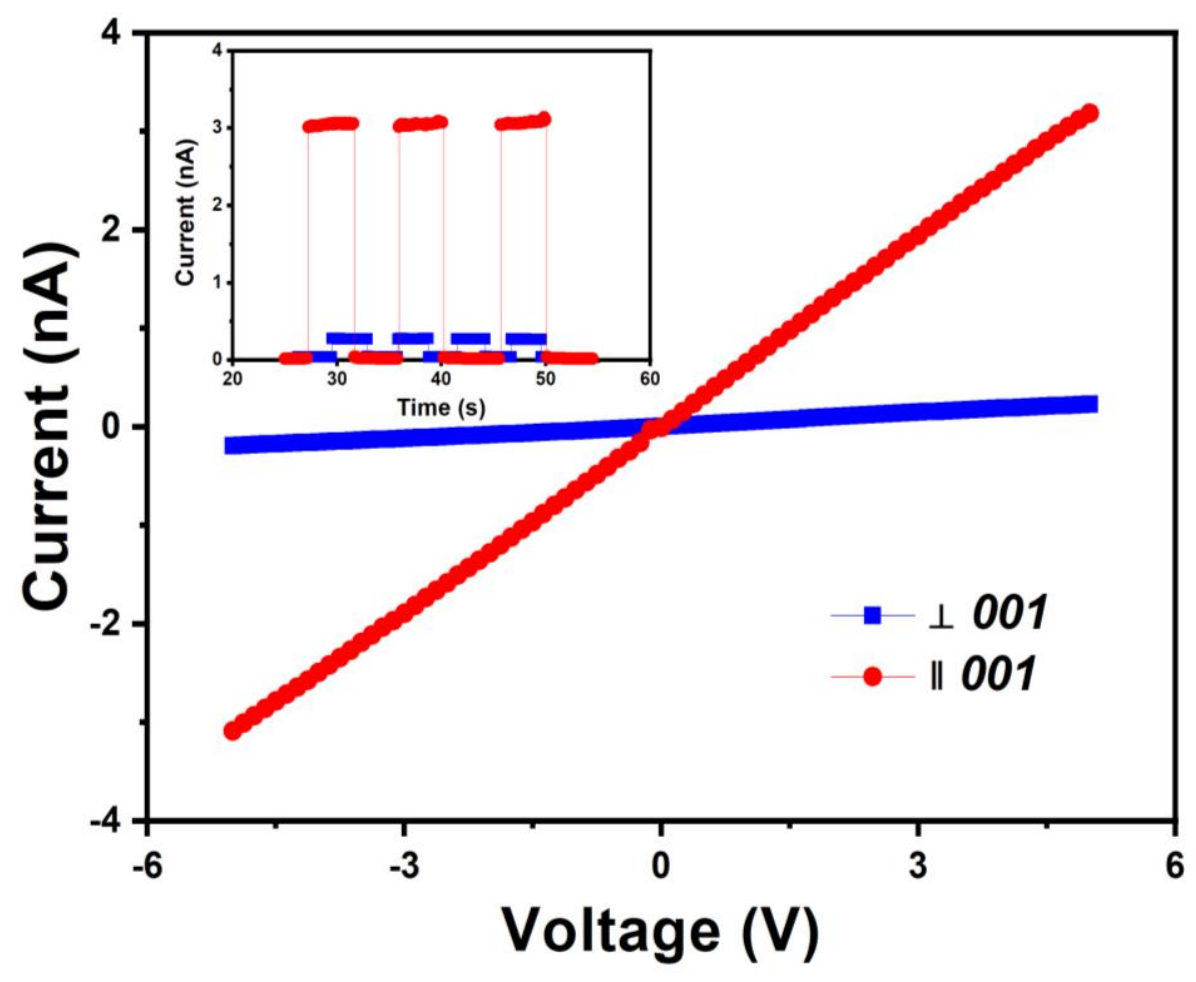

Figure S17. The $I-V$ characteristics of perovskite II along and perpendicular to 001 axes, measured under a $405 \mathrm{~nm}$ light illumination with the light intensity of $100 \mathrm{~m}$ $\mathrm{Wcm}^{-2}$ at room temperature. Inset: Time-dependent photoresponse of the crystal-based photodetectors measured along and perpendicular to 001 axes by periodically turning on and off a $405 \mathrm{~nm}$ monochromatic laser at a bias of $5 \mathrm{~V}$.

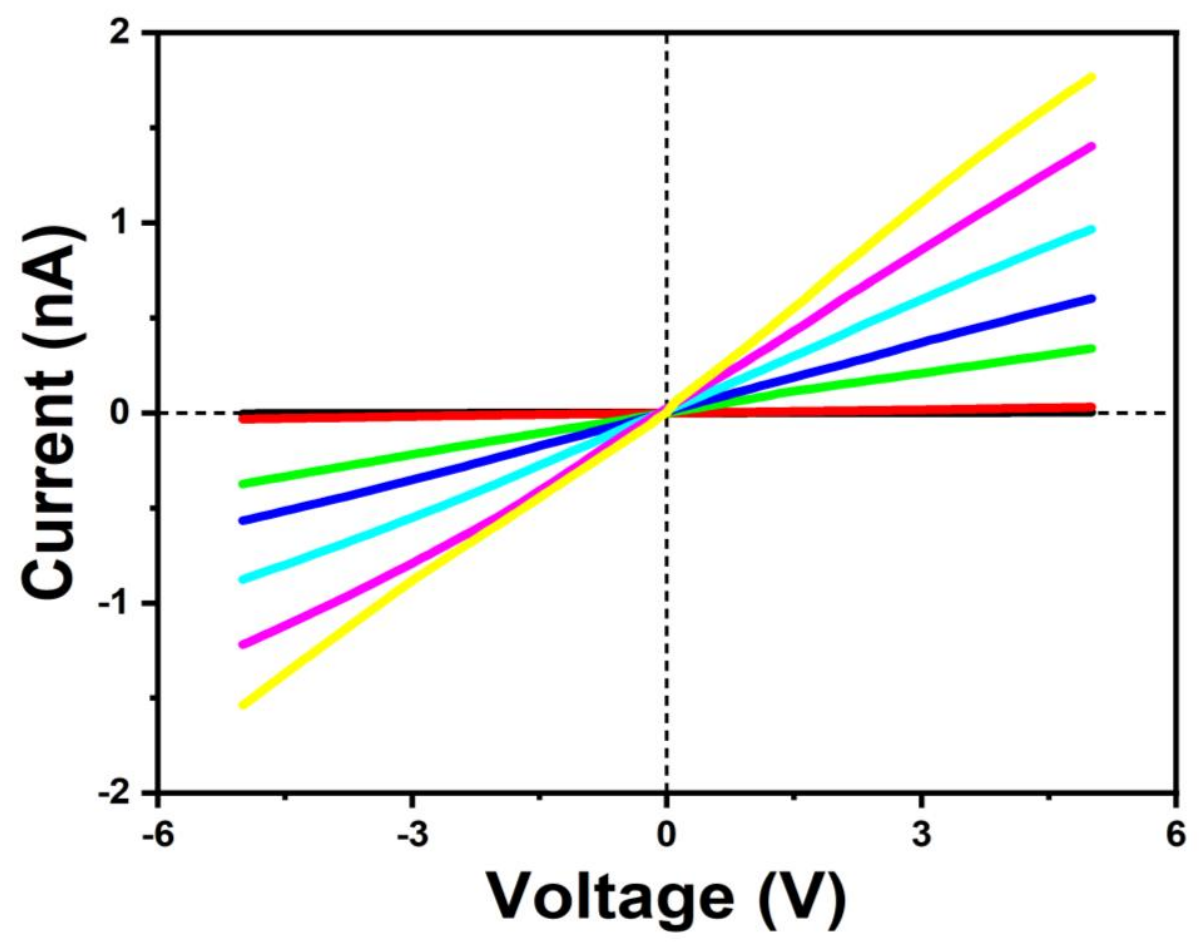

Figure S18. $I-V$ characteristics of perovskite $\mathbf{I I}$ for the crystal devices within the 0-degree incident polarized-light power density ranging from $8.5 \mathrm{~mW}$ cm ${ }^{-2}$ to 85.1 $\mathrm{mW} \mathrm{cm}$ at wavelength $405 \mathrm{~nm}$ under a fixed $5 \mathrm{~V}$ bias. The experimental ambient is room temperature conditions. 
a

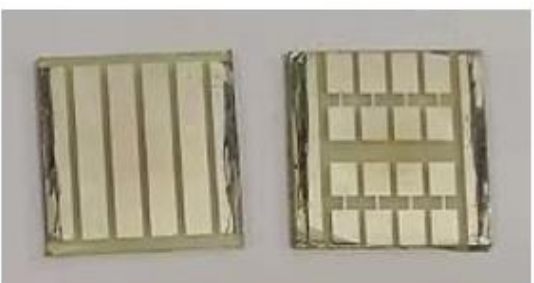

b Ag

\section{Perovskite}

\section{PTAA}

ITO

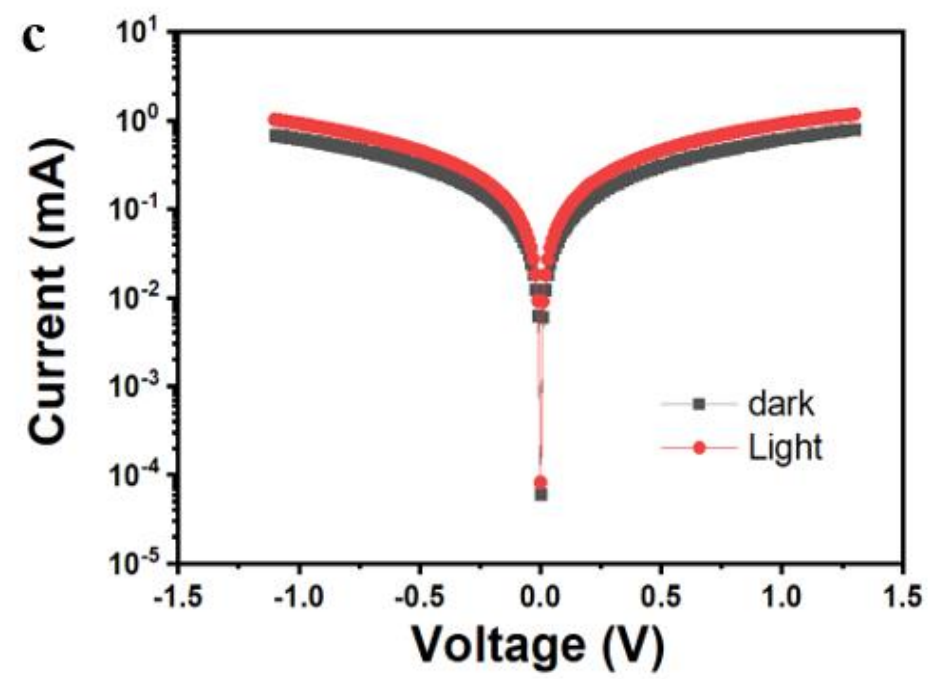

Figure S19. Film devices of perovskite II. (a) Image of the investigated devices. (b) Device architecture. (c) The $I-V$ characteristics, measured in dark and 1 -sun light illumination.

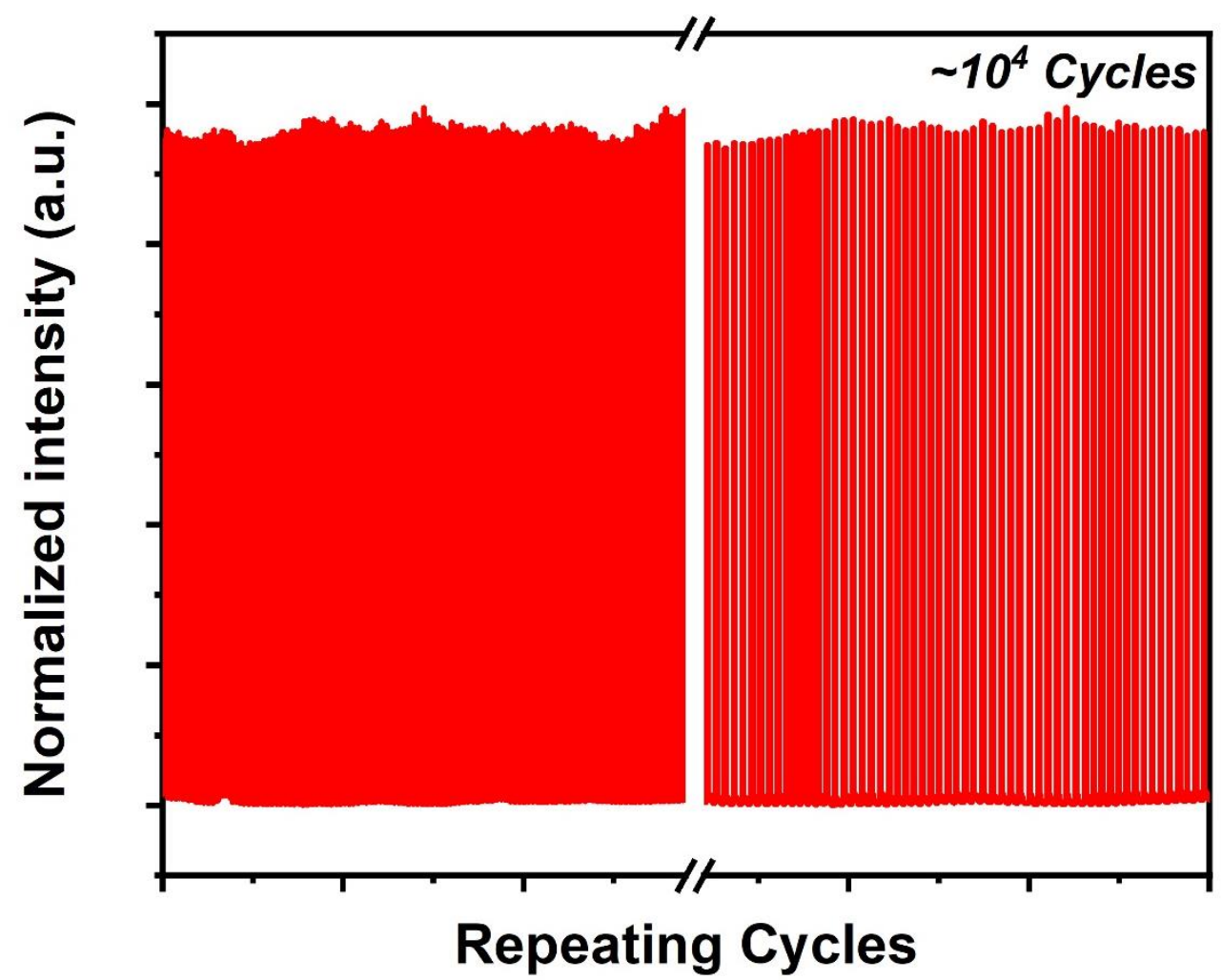

Figure S20. Long-time repeative switching cycles of photoresponse based on the crystal devices of perovskite II. The experimental ambient is room temperature conditions. 


\subsection{Polarized-light detection performances}
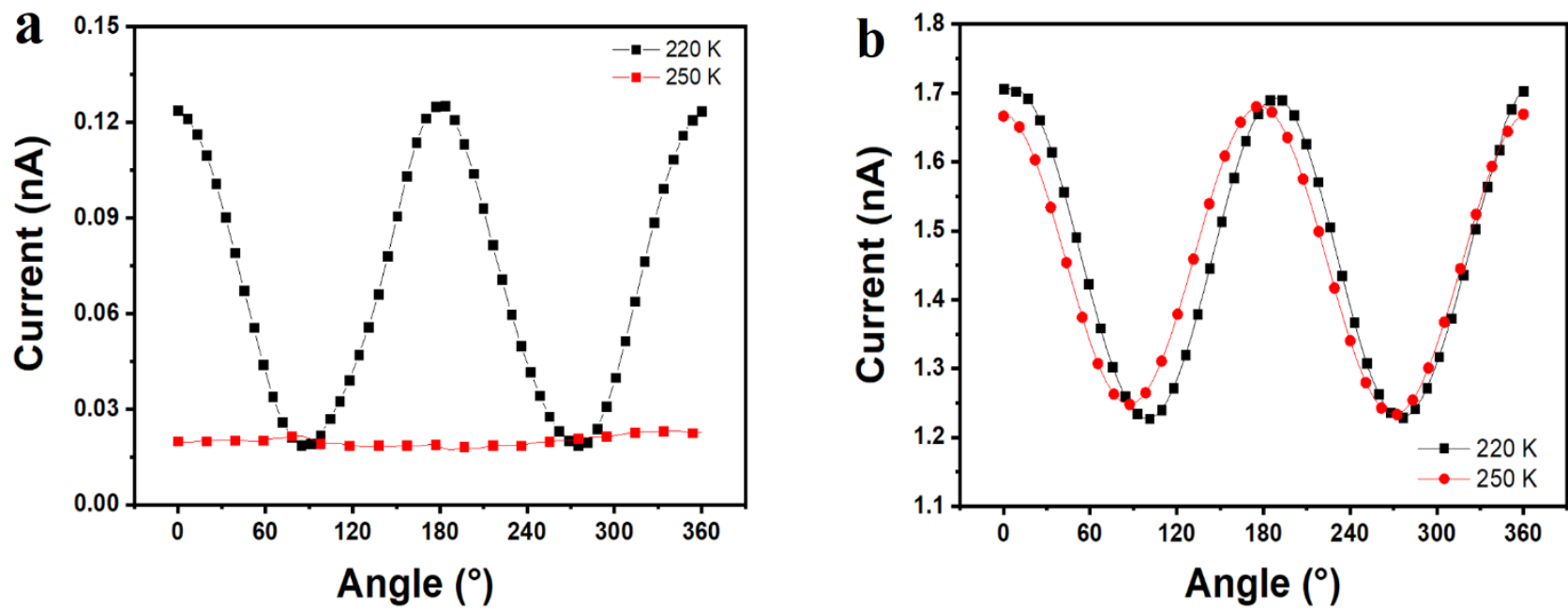

Figure S21. Polarized-light behaviors of perovskite II. (a) Ferroelectricity-driven polarization-dependent photocurrent at the ferroelectric phase, comparing with the corresponding polarization performance at the paraelectric phase. (b) Voltage-driven polarization-dependent photocurrents at ferroelectric and paraelectric phase.

Figure S21a displays the angle- resolved $I_{\mathrm{sc}}$ curves under $405 \mathrm{~nm}$ light illumination. As shown in the polar coordinate, $I_{\mathrm{sc}}$ reaches the maximum when the light is polarized along the (001) direction. In contrast, when the polarization direction is perpendicular to the (001) direction, $I_{\mathrm{sc}}$ decreases to the minimum value. It reconfirms that ferroelectricity can drive the generation of polarization-dependent photocurrent for the application of polarization photodetection without offering extra voltage. As a result, a polarization ratio of $R_{\mathrm{p}}=I_{\max } / I_{\min }$, where $I_{\max }$ and $I_{\min }$ are photocurrent maximum and minimum at $0^{\circ}$ and $90^{\circ}$ polarizations, was estimated to be about 6.9. The current along (001) direction in ferroelectric- base device exhibits an angle- dependence on light polarization, which can be described by the equation $J_{\mathrm{c}}=I \beta_{31} \sin ^{2}(\theta)+I \beta_{33} \cos ^{2}(\theta)$, where $J_{\mathrm{c}}$ is the photovoltaic current density along the polar axis (c-axis), $I$ is light intensity, and $\theta$ is the angle between light polarization plane and polar axis. ${ }^{14} 15$ When the polarized light is in a direction perpendicular to $P_{\mathrm{s}}$, the constant $\beta_{31}$ is about 0 , and the coupling between ferroelectricity and the optical field is weak, resulting in negligible bulk photovoltaic effect and ultra- low $I_{\min }$. Conversely, when light polarizes in a direction parallel to $P_{\mathrm{s}}$, the strong lightmatter interaction between incident light and $P_{\mathrm{s}}$ arouses significant bulk photovoltaic effect response and large photovoltaic current $I_{\max }$, eventually resulting in highly sensitive polarized photodetection with a large polarization ratio. Therefore, the ferroelectricity- driven polarized behavior is disappeared at the paraelectric phase.

By contrast, optical polarization is the difference between the absorption of light polarized along the perpendicular and parallel directions with respect to a specific orientation axis of a natural or artificial crystal. Under the ferroelectric phase, both optical polarization and ferroelectric polarization work together in polarized photodetection. However, ferroelectricity- driven photocurrent is much smaller than the voltage-driven photocurrent (Figure S21a and S21b). Therefore, in contrast to the paraelectric phase, the polarized behavior changes little in the ferroelectric phase, as shown in Figure S21b. 


\section{Tables}

Table S1 Crystal data.

\begin{tabular}{|c|c|c|c|}
\hline \multirow{2}{*}{$\begin{array}{l}\text { Empirical formula } \\
\text { Formula weight }\end{array}$} & \multicolumn{2}{|c|}{ (n-propylammonium)(methylammonium) $\mathrm{SbBr}_{5}$} & \multirow{2}{*}{$\begin{array}{l}\text { (n-propylammonium) } \mathrm{SbBr}_{5} \\
641.54\end{array}$} \\
\hline & 613.49 & 613.49 & \\
\hline Temperature/K & 199.9 & 260.02 & 99.97 \\
\hline Crystal system & orthorhombic & orthorhombic & orthorhombic \\
\hline Space group & Pna $2_{1}$ & Pnma & Pnma \\
\hline $\mathrm{a} / \AA$ & $15.3881(4)$ & $15.4580(12)$ & $7.9843(8)$ \\
\hline $\mathrm{b} / \AA$ & $12.4243(3)$ & $7.8641(5)$ & $14.5577(17)$ \\
\hline $\mathrm{c} / \AA$ & $7.8589(2)$ & $12.5222(7)$ & $14.5268(14)$ \\
\hline$\alpha /^{\circ}$ & 90 & 90 & 90 \\
\hline$\beta /{ }^{\circ}$ & 90 & 90 & 90 \\
\hline$\gamma^{/ \circ}$ & 90 & 90 & 90 \\
\hline Volume $/ \AA^{3}$ & $1502.51(7)$ & $1522.24(17)$ & $1688.5(3)$ \\
\hline $\mathrm{Z}$ & 4 & 4 & 4 \\
\hline$\rho c a l c g / \mathrm{cm}^{3}$ & 2.712 & 2.677 & 2.524 \\
\hline$\mu / \mathrm{mm}^{-1}$ & 15.099 & 14.903 & 13.442 \\
\hline $\mathrm{F}(000)$ & 1120.0 & 1120.0 & 1184.0 \\
\hline Radiation (MoK $\alpha$ ) & 0.71073 & 0.71073 & 0.71073 \\
\hline $2 \underline{\theta}$ range for data collection $/^{\circ}$ & 5.184 to 54.998 & 5.27 to 54.978 & 5.608 to 52.798 \\
\hline Reflections collected & 12749 & 12267 & 6106 \\
\hline Data/restraints/parameters & $3364 / 1 / 114$ & $1873 / 18 / 80$ & $1430 / 0 / 72$ \\
\hline Goodness-of-fit on $\mathrm{F}^{2}$ & 1.102 & 1.179 & 1.099 \\
\hline Final $\mathrm{R}$ indexes $[\mathrm{I}>=2 \sigma(\mathrm{I})]$ & $\mathrm{R} 1=0.0417$ & 0.0669 & 0.0593 \\
\hline $\mathrm{R}_{1 \mathrm{a}} \& w \mathrm{R}_{2 \mathrm{~b}}$ & $w R 2=0.0968$ & 0.1499 & 0.1491 \\
\hline CCDC & 1946541 & 1946540 & 1978435 \\
\hline
\end{tabular}

${ }^{a} R\left(F_{0}\right)=\sum|| F_{0}|-| F_{c}|| \sum\left|F_{0}\right| . \quad{ }^{b} R_{w}\left(F_{0}\right)=\left(\sum w|| F_{0}|-| F_{c}||^{2} / \Sigma\left|F_{0}\right|^{2}\right)^{1 / 2}, w=\left[\sigma^{2}\left(F_{0}\right)+\left(0.002 F_{0}\right)^{2}\right]^{-1}$

Note: Please refer to CCDC for other crystal structure data, including the codes $2102644\left[\left(\mathrm{C}_{6} \mathrm{H}_{5} \mathrm{CHNHC}_{3} \mathrm{H}_{7}\right)_{2}\left(\mathrm{C}_{3} \mathrm{H}_{7} \mathrm{NH}_{3}\right) \mathrm{Bi}_{2} \mathrm{Br}_{9}\right]$ and 2102645 [(ethylammonium)(benzylammonium $\left.)_{2} \mathrm{Bi}_{2} \mathrm{Br}_{9}\right]$.

Table S2. The main parameters of crystal-based photodetectors.

\begin{tabular}{|c|c|c|c|c|}
\hline Device architecture & Detection spectrum & $\mathrm{I}_{\text {dark }}(\mathrm{A})$ & On/off & Ref \\
\hline $\mathrm{Au} / \mathrm{MA}_{3} \mathrm{Sb}_{2} \mathrm{I}_{9} / \mathrm{Au}$ & $460 \mathrm{~nm}, 100 \mathrm{~mW} / \mathrm{cm}^{2}$ & $6 \times 10^{-9}$ & $<4$ & 16 \\
\hline $\mathrm{Ag} /(\mathrm{N} \text {-methylpyrrolidinium })_{3} \mathrm{Sb}_{2} \mathrm{Br}_{9} / \mathrm{Ag}$ & $365 \mathrm{~nm}, 20 \mathrm{~mW} / \mathrm{cm}^{2}$ & $2.3 \times 10^{-11}$ & $\sim 2.5$ & 17 \\
\hline $\mathrm{Cs}_{3} \mathrm{Bi}_{2} \mathrm{I}_{9} / \mathrm{Pd}$ & $405 \mathrm{~nm}, 50 \mathrm{~mW} / \mathrm{cm}^{2}$ & $2 \times 10^{-11}$ & 10.50 & 18 \\
\hline $\mathrm{Cs}_{3} \mathrm{Sb}_{2} \mathrm{I}_{9} / \mathrm{C}$ & & $5 \times 10^{-10}$ & 9.39 & \\
\hline $\mathrm{Rb}_{3} \mathrm{Bi}_{2} \mathrm{I}_{9} / \mathrm{C}$ & & $1.4 \times 10^{-9}$ & 2.95 & \\
\hline $\mathrm{Rb}_{3} \mathrm{Sb}_{2} \mathrm{I}_{9} / \mathrm{Au}$ & & $1 \times 10^{-8}$ & 1.03 & \\
\hline (tetramethylpiperazine) ${ }_{3} \mathrm{Bi}_{4} \mathrm{I}_{14} \mathrm{Cl}_{4}$ & xenon lamp, $450 \mathrm{~W}$ & $2.5 \times 10^{-7}$ & 2.2 & 19 \\
\hline $\mathrm{CsPbBr} / \mathrm{Au}$ & $450 \mathrm{~nm}, 20 \mathrm{~mW}$ & $7.98 \times 10^{-8}$ & $\sim 100$ & 20 \\
\hline $\mathrm{MAPbI}_{3} / \mathrm{Au}$ & $405 \mathrm{~nm}, 5 \mathrm{~mW}$ & $>1.41 \times 10^{8}$ & - & 21 \\
\hline Glass/ $\mathrm{BA}_{2} \mathrm{MAPb}_{2} \mathrm{I}_{7} / \mathrm{Au}$ & white light, $3.0 \mathrm{~mW} / \mathrm{cm}^{2}$ & $\sim 1 \times 10^{-11}$ & 250 & 22 \\
\hline $\mathrm{Au} /\left(n\right.$-propylammonium)(methylammonium) $\mathrm{SbBr}_{5} / \mathrm{Au}$ & $405 \mathrm{~nm}, 100 \mathrm{~mW} / \mathrm{cm}^{2}$ & $3.1 \times 10^{-11}$ & $\sim 500$ & This work \\
\hline
\end{tabular}


Table S3. Performance comparison of crystal-II devices with reported anisotropic photodetectors.

\begin{tabular}{|c|c|c|c|}
\hline Device architecture & Detection spectrum & Anisotropy ratio & Ref \\
\hline Quasi-1D TiS 3 /Si heterojunction & $660 \mathrm{~nm}, \mathrm{~V}=-0.5 \mathrm{~V} / 0 \mathrm{~V}$ & $0.29 / 0.44$ & 23 \\
\hline 2D $\operatorname{ReS}_{2}$ & $405 \mathrm{~nm}, \mathrm{~V}=1 \mathrm{~V}$ & 0.5 & \\
\hline 2D $\operatorname{ReSe}_{2}$ & $633 \mathrm{~nm}, \mathrm{~V}=0.5 \mathrm{~V}$ & 0.33 & \\
\hline 2D GeS & $500 \mathrm{~nm}, \mathrm{~V}=4 \mathrm{~V}$ & $>0.9$ & \\
\hline $1 \mathrm{D} \ln \mathrm{P}$ & N/A & 0.96 & \\
\hline 2D Black phosphorus/ $\mathrm{MoS}_{2}$ & $532 \mathrm{~nm}, \mathrm{~V}=2 \mathrm{~V}$ & 0.43 & \\
\hline 2D Black phosphorus/WSe ${ }_{2}$ & $1550 \mathrm{~nm}, \mathrm{~V}=0.5 \mathrm{~V}$ & 0.71 & \\
\hline 2D germanium arsenic (GeAs) & $520 \mathrm{~nm}, \mathrm{~V}=10 \mathrm{mV}$ & 1.49 & 24 \\
\hline 2D $\mathrm{GeS}_{2}$ flake & $325 \mathrm{~nm}, \mathrm{~V}=10 \mathrm{~V}$ & 2.1 & 25 \\
\hline 2D Few-layer Black Phosphorus-InSe & $633 \mathrm{~nm}, \mathrm{~V}=0 \mathrm{~V}$ & 0.83 & 26 \\
\hline 2D $\mathrm{MoS}_{2}$ nanosheet & $660 \mathrm{~nm}, \mathrm{~V}=1 \mathrm{~V}$ & 1.45 & 27 \\
\hline 2D GeSe & $532 \mathrm{~nm}, \mathrm{~V}=2 \mathrm{~V}$ & 1.09 & 28 \\
\hline 2D Black phosphorus & $1200 \mathrm{~nm}, \mathrm{~V}=0.1 \mathrm{~V}$ & 3.5 & 29 \\
\hline Quasi-1D Sn ${ }^{\mathrm{II}} \mathrm{Sn}^{\mathrm{I}} \mathrm{VS}_{3}$ microcrystal & $532 \mathrm{~nm}, \mathrm{~V}=2 \mathrm{~V}$ & 1.3 & 30 \\
\hline $1 \mathrm{D} \mathrm{CsCu} \mathrm{I}_{3}$ nanowires $(600 \mathrm{~nm})$ & $325 \mathrm{~nm}, \mathrm{~V}=1.0 \mathrm{~V}$ & 3.16 & 31 \\
\hline $1 \mathrm{D} \mathrm{CsCu} \mathrm{I}_{3}$ micronwires $(6.0 \mu \mathrm{m})$ & & 1.24 & \\
\hline $1 \mathrm{D} \mathrm{GeO}_{2^{-}}-$Ge nanowire & $514 \mathrm{~nm}$ & 0.62 & 32 \\
\hline $1 \mathrm{D} \mathrm{Cs} \mathrm{PbBr}_{3}$ perovskite arrays. & $470 \mathrm{~nm}, \mathrm{~V}=5 \mathrm{~V}$ & 2.6 & 33 \\
\hline $2 \mathrm{D}$ (ethylammoniumion) $)_{2}$ (methylammonium $)_{2} \mathrm{~Pb}_{3} \mathrm{Cl}_{10}$ bulk crystal & $266 \mathrm{~nm}, \mathrm{~V}=10 \mathrm{~V}$ & 1.38 & 34 \\
\hline $2 \mathrm{D}$ (isopentylammonium) ${ }_{2} \mathrm{CsAgBiBr}_{7}$ bulk crystal & $405 \mathrm{~nm}, \mathrm{~V}=10 \mathrm{~V}$ & 1.35 & 35 \\
\hline $2 \mathrm{D}$ (n-butylammonium) $)_{2}$ (methylammonium) $\mathrm{Pb}_{2} \mathrm{Br}_{7}$ bulk crystal & $405 \mathrm{~nm}, \mathrm{~V}=10 \mathrm{~V}$ & $\approx 2.0$ & 36 \\
\hline $1 \mathrm{D}$ (n-propylammonium)(methylammonium)SbBr 5 bulk crystal & $405 \mathrm{~nm}, \mathrm{~V}=5 \mathrm{~V}$ & 1.31 & This work \\
\hline
\end{tabular}




\section{References}

(1) Sheldrick, G. M., A short history of SHELX. Acta Crystallogr A 2008, 64 (Pt 1), 112-122.

(2) Müller, P.; Herbst-Irmer, R.; Spek, A. L.; Schneider, T. R.; Sawaya, M. R., Crystal Structure Refinement: A Crystallographer's Guide to SHELXL. 2006.

(3) Sheldrick, G. M., SHELXS-97, Program for Solution of Crystal Structures (University of Göttingen, Germany). 1997.

(4) Sheldrick, G. M., SHELXT - integrated space-group and crystal-structure determination. Acta Crystallogr A Found Adv 2015,71 (Pt 1), 3-8.

(5) Kubelka, P.; Munk, F. Z., An Article on Optics of Paint Layers. Z. Technol. Phys. 1931, 12, 593-601.

(6) Segall, M. D.; Lindan, P. J. D.; Probert, M. J.; Pickard, C. J.; Hasnip, P. J.; Clark, S. J.; Payne, M. C., First-principles simulation: ideas, illustrations and the CASTEP code. J. Phys.: Condens. Matter 2002, 14 (11), 2717-2744.

(7) Clark, S. J.; Segall, M. D.; Pickard, C. J.; Hasnip, P. J.; Probert, M. J.; Refson, K.; Payne, M. C., First-principles simulation: ideas, illustrations and the CASTEP code. Z. Kristallogr. - Cryst. Mater. 2005, 220, 567-667.

(8) Perdew, J. P.; Ruzsinszky, A.; Csonka, G. I.; Vydrov, O. A.; Scuseria, G. E.; Constantin, L. A.; Zhou, X.; Burke, K., Restoring the density-gradient expansion for exchange in solids and surfaces. Phys Rev Lett 2008, 100 (13), 136406.

(9) Hamann, D. R.; Schlüter, M.; Chiang, C., Norm-Conserving Pseudopotentials. Physical Review Letters 1979, 43 (20), $1494-1497$.

(10) Jakubas, R.; Sobczyk, L.; Matuszewski, J., Ferroelectricity and phase transitions in tris (dimethylammonium) nonabromodiantimonate (III). Ferroelectrics 1987, 74 (1), 339-345.

(11) Jakubas, R.; Ga Gor, A.; Winiarski, M. J.; Ptak, M.; Piecha-Bisiorek, A.; Cizman, A., Ferroelectricity in Ethylammonium BismuthBased Organic-Inorganic Hybrid: $\left(\mathrm{C}_{2} \mathrm{H}_{5} \mathrm{NH}_{3}\right)_{2}\left[\mathrm{BiBr}_{5}\right.$. Inorg Chem 2020, 59 (6), 3417-3427.

(12) Liu, X.; Xu, Z.; Long, P.; Yao, Y.; Ji, C.; Li, L.; Sun, Z.; Hong, M.; Luo, J., A Multiaxial Layered Halide Double Perovskite Ferroelectric with Multiple Ferroic Orders. Chemistry of Materials 2020, 32 (20), 8965-8970.

(13) Zhang, W.; Hong, M.; Luo, J., Halide Double Perovskite Ferroelectrics. Angew. Chem. Int. Ed. 2020, 59 (24), $9305-9308$.

(14) Fridkin, V. M.; Magomadov, R. M., Anomalous photovoltaic effect in LiNbO3:Fe in polarized light. . JETP Lett. 1979, 30, 686-688.

(15) Fridkin, V. M., Photoferroelectrics. Springer, Berlin 1979, 9.

(16) Yang, B.; Li, Y. J.; Tang, Y. X.; Mao, X.; Luo, C.; Wang, M. S.; Deng, W. Q.; Han, K. L., Constructing Sensitive and Fast LeadFree Single-Crystalline Perovskite Photodetectors. J. Phys. Chem. Lett. 2018, 9 (11), 3087-3092.

(17) Sun, Z.; Zeb, A.; Liu, S.; Ji, C.; Khan, T.; Li, L.; Hong, M.; Luo, J., Exploring a Lead-free Semiconducting Hybrid Ferroelectric with a Zero-Dimensional Perovskite-like Structure. Angew. Chem. Int. Ed. 2016, 55 (39), 11854-8.

(18) McCall, K. M.; Stoumpos, C. C.; Kostina, S. S.; Kanatzidis, M. G.; Wessels, B. W., Strong Electron-Phonon Coupling and SelfTrapped Excitons in the Defect Halide Perovskites $\mathrm{A}_{3} \mathrm{M}_{2} \mathrm{I}_{9}(\mathrm{~A}=\mathrm{Cs}, \mathrm{Rb} ; \mathrm{M}=\mathrm{Bi}$, Sb). Chemistry of Materials 2017, 29 (9), $4129-4145$.

(19) Li, M.-Q.; Hu, Y.-Q.; Bi, L.-Y.; Zhang, H.-L.; Wang, Y.; Zheng, Y.-Z., Structure Tunable Organic-Inorganic Bismuth Halides for an Enhanced Two-Dimensional Lead-Free Light-Harvesting Material. Chemistry of Materials 2017, 29 (13), 5463-5467.

(20) Ding, J.; Du, S.; Zuo, Z.; Zhao, Y.; Cui, H.; Zhan, X., High Detectivity and Rapid Response in Perovskite CsPbBr3 Single-Crystal Photodetector. The Journal of Physical Chemistry C 2017, 121 (9), 4917-4923.

(21) Ding, J.; Du, S.; Cheng, X.; Jing, L.; Zhao, Y.; Zuo, Z.; Cui, H.; Zhan, X., Anisotropic optoelectronic performances on (112) and (100) lattice plane of perovskite $\mathrm{MAPbI}_{3}$ single crystal. Materials Chemistry and Physics 2018, 204, 222-227.

(22) Tong, X.-W.; Kong, W.-Y.; Wang, Y.-Y.; Zhu, J.-M.; Luo, L.-B.; Wang, Z.-H., High-Performance Red-Light Photodetector Based on Lead-Free Bismuth Halide Perovskite Film. ACS Appl. Mater. Interfaces 2017, 9 (22), 18977-18985.

(23) Niu, Y.; Frisenda, R.; Flores, E.; Ares, J. R.; Jiao, W. C.; $\quad$ de Lara, D. P.; Sanchez, C.; Wang, R. G.; Ferrer, I. J.; CastellanosGomez, A., Polarization-Sensitive and Broadband Photodetection Based on a Mixed-Dimensionality TiS $3 /$ Si p-n Junction. Advanced Optical Materials 2018, 6 (19), 1800351.

(24) Zhou, Z.; Long, M.; Pan, L.; Wang, X.; Zhong, M.; Blei, M.; Wang, J.; Fang, J.; Tongay, S.; Hu, W.; Li, J.; Wei, Z., Perpendicular Optical Reversal of the Linear Dichroism and Polarized Photodetection in 2D GeAs. ACS Nano 2018, 12 (12), $12416-12423$. (25) Yang, Y.; Liu, S. C.; Wang, X.; Li, Z.; Zhang, Y.; Zhang, G.; Xue, D. J.; Hu, J. S., Polarization- Sensitive Ultraviolet Photodetection of Anisotropic 2D GeS2. Adv. Funct. Mater. 2019, 29 (16), 1900411.

(26) Zhao, S.; Wu, J.; Jin, K.; Ding, H.; Li, T.; Wu, C.; Pan, N.; Wang, X., Highly Polarized and Fast Photoresponse of Black Phosphorus-InSe Vertical p-n Heterojunctions. Adv. Funct. Mater. 2018, 28 (34), 1802011.

(27) Chen, S.; Cao, R.; Chen, X.; Wu, Q.; Zeng, Y.; Gao, S.; Guo, Z.; Zhao, J.; Zhang, M.; Zhang, H., Anisotropic Plasmonic Nanostructure Induced Polarization Photoresponse for $\mathrm{MoS}_{2}$-Based Photodetector. Adv. Mater. Interfaces 2020, 7 (9), 1902179.

(28) Wang, X.; Li, Y.; Huang, L.; Jiang, X. W.; Jiang, L.; Dong, H.; Wei, Z.; Li, J.; Hu, W., Short-Wave Near-Infrared Linear Dichroism of Two-Dimensional Germanium Selenide. J. Am. Chem. Soc. 2017, 139 (42), 14976-14982.

(29) Yuan, H.; Liu, X.; Afshinmanesh, F.; Li, W.; Xu, G.; Sun, J.; Lian, B.; Curto, A. G.; Ye, G.; Hikita, Y.; Shen, Z.; Zhang, S. C.; Chen, X.; Brongersma, M.; Hwang, H. Y.; Cui, Y., Polarization-sensitive broadband photodetector using a black phosphorus vertical p-n junction. Nat. Nanotechnol. 2015, 10 (8), 707-13.

(30) Yang, H.; Pan, L.; Wang, X.; Deng, H. X.; Zhong, M.; Zhou, Z.; Lou, Z.; Shen, G.; Wei, Z., Mixed- Valence- Driven Quasi1D Sn ${ }^{\mathrm{II}} \mathrm{Sn}^{\mathrm{IV}} \mathrm{S}_{3}$ with Highly Polarization- Sensitive UV-vis-NIR Photoresponse. Adv. Funct. Mater. 2019, 29 (38), 1904416.

(31) Li, Y.; Shi, Z.; Wang, L.; Chen, Y.; Liang, W.; Wu, D.; Li, X.; Zhang, Y.; Shan, C.; Fang, X., Solution-processed onedimensional $\mathrm{CsCu}_{2} \mathrm{I}_{3}$ nanowires for polarization-sensitive and flexible ultraviolet photodetectors. Mater. Horiz. 2020, 7 (6), $1613-1622$.

(32) Mukherjee, S.; Das, K.; Das, S.; Ray, S. K., Highly Responsive, Polarization Sensitive, Self-Biased Single GeO ${ }_{2}$-Ge Nanowire Device for Broadband and Low Power Photodetectors. ACS Photonics 2018, 5 (10), 4170-4178.

(33) Feng, J.; Yan, X.; Liu, Y.; Gao, H.; Wu, Y.; Su, B.; Jiang, L., Crystallographically Aligned Perovskite Structures for HighPerformance Polarization-Sensitive Photodetectors. Adv. Mater. 2017, 29 (16), 1605993.

(34) Xu, Z.; Weng, W.; Li, Y.; Liu, X.; Yang, T.; Li, M.; Huang, X.; Luo, J.; Sun, Z., 3D-to-2D Dimensional Reduction for Exploiting a Multilayered Perovskite Ferroelectric toward Polarized-Light Detection in the Solar-Blind Ultraviolet Region. Angew. Chem. Int. Ed. 2020, 59 (48), 21693-21697.

(35) Li, Y.; Yang, T.; Xu, Z.; Liu, X.; Huang, X.; Han, S.; Liu, Y.; Li, M.; Luo, J.; Sun, Z., Dimensional Reduction of $\mathrm{Cs}_{2} \mathrm{AgBiBr}_{6}$ : A 2D Hybrid Double Perovskite with Strong Polarization Sensitivity. Angew. Chem. Int. Ed. 2020, 59 (9), $3429-3433$.

(36) Li, L.; Liu, X.; Li, Y.; Xu, Z.; Wu, Z.; Han, S.; Tao, K.; Hong, M.; Luo, J.; Sun, Z., Two-Dimensional Hybrid PerovskiteType Ferroelectric for Highly Polarization-Sensitive Shortwave Photodetection. J. Am. Chem. Soc. 2019, 141 (6), 2623-2629. 